\title{
Resource Allocation Decisions under Imperfect Evaluation and Organizational Dynamics
}

\author{
Jochen Schlapp ${ }^{1}$, Nektarios Oraiopoulos ${ }^{2}$, Vincent Mak $^{2}$ \\ ${ }^{1}$ Business School, University of Mannheim, Mannheim 68163, Germany, \\ jschlapp@bwl.uni-mannheim.de \\ ${ }^{2}$ Judge Business School, Cambridge University, Cambridge CB2 1AG, United Kingdom, \\ n.oraiopoulos@jbs.cam.ac.uk,v.mak@jbs.cam.ac.uk
}

September 24, 2014

Forthcoming in Management Science

\begin{abstract}
$R \& D$ projects face significant organizational challenges, especially when the different units who run these projects compete among each other for resources. In such cases, information sharing among the different units is critical, but it cannot be taken for granted. Instead, individual units need to be incentivized to not only exert effort in evaluating their projects, but also to truthfully reveal their findings. The former requires an emphasis on individual performance, while the latter relies on the existence of a common goal across the organization. Motivated by this commonly observed tension, we address the following question: how should a firm balance individual and shared incentives, so that vital information is both acquired, and equally importantly, disseminated to the entire organization? Our model captures two key characteristics of $R \& D$ experimentation: information is imperfect and it is also costly. Our analysis yields several important implications for the design of such incentive schemes and the management of R\&D portfolios.
\end{abstract}

Key words: new product development, resource allocation processes, product evaluation, incentives, $\mathrm{R} \& \mathrm{D}$ portfolio

\section{Introduction}

Launching new products has always been a daunting task even for the most successful organizations. Scholars early on highlighted that given the high uncertainty embedded in such projects, identifying the "winners" upfront is rather unlikely, and as such, committing substantial resources early on may not always be the most prudent strategy. Instead, scholars suggest that a firm should engage in parallel pursuits, and refine its resource allocation decisions as more information becomes available (Nelson, 1961). A parallel search approach allows a firm 
to explore a much broader set of ideas (Kornish and Ulrich, 2011), develop a much more robust and adaptable business strategy (Beinhocker, 1999), and gain a competitive advantage in environments characterized by unforeseeable uncertainty and complex performance landscapes (Sommer and Loch, 2004). Despite these indisputable benefits, the management of parallel projects involves substantial challenges (Sommer et al., 2009). A fundamental one stems from the fact that these projects often co-exist within a product portfolio, and therefore, compete with each other for the same scarce resources. This challenge is widespread in companies that manage parallel projects and is nicely summarized in Sharpe and Keelin (1998, p. 45): "how do you make good decisions, in a high-risk, technically complex business when the information you need to make those decisions comes largely from the project champions who are competing against one another for resources?" This is the primary question we address in this paper.

This question is particularly relevant in industries where tough resource allocation decisions need to be made. For example, given its skyrocketing costs and its highly uncertain nature, the pharmaceutical industry has been struggling to improve its decision making processes. Consider the recent restructuring of GlaxoSmithKline (GSK) discussed in Huckman and Strick (2010). When GlaxoWellcome and SmithKline Beecham merged in 2000, the new company announced the creation of six independent Centers of Excellence for Drug Discovery (CEDD) focused on different therapeutic areas, a unique concept that sought to bring the entrepreneurial culture of a biotech R\&D to the gigantic new company. If a compound progressed through Phase IIa, the leadership of the CEDD unit would present the compound to the centralized Development Investment Board (DIB) which would ultimately decide whether the compound would receive the substantial resources required to progress to Phase IIb. A key aspect of this restructuring was the incentive scheme which, in an effort to promote independence and mimic small biotech companies, offered substantial rewards to scientists and executives for progressing compounds that originated from their own CEDD. Naturally, this policy raised serious concerns about the emergence of ferocious competition among the different CEDDs.

A diametrically opposite reward structure was adopted by Wyeth Pharmaceuticals (Huckman et al., 2010). The fundamental premise of Wyeth's restructuring efforts was to motivate scientists to look beyond their departmental "silos" and strengthen synergies across the various therapeutic areas, and as such, the bonuses of all eligible scientists in R\&D were based on the degree to which the entire organization achieved its objectives. In general, promoting such synergies is perceived to be beneficial for organizations, but in the case of running parallel projects it is often considered absolutely vital as such shared incentives facilitate better communication across the organization. This is stressed in Loch et al. (2006, ch. 6) who argue that the successful implementation of running parallel projects critically relies on the ability of top management to elicit credible information from their product development teams, and subsequently disseminate this information to the rest of the organization. This information, in turn, is the key to efficient resource allocation decisions that strengthen "star" projects and abandon "flops". Under this collective reward policy, however, a key concern at Wyeth was that it failed to reward exceptional achievements by specific project teams. 
The goal of this paper is to understand how a firm should design its incentive schemes in order to balance these two opposing forces: to incentivize individual project teams to exert effort to improve the evaluation of their own projects with the need to achieve cooperation and information sharing across the different project teams. Specifically, and given the informationintensive nature of such resource allocation decision processes, we address the following question: how can a firm balance individual and shared incentives, so that its product managers are willing to acquire the necessary information, and equally importantly, to share it with the rest of the organization?

It is worth noting that in such highly technical and complex environments as the ones faced in the pharmaceutical industry, neither the acquisition nor the dissemination of reliable information can be dictated by traditional top-down management approaches. As Sharpe and Keelin (1998) explain, traditional top-down approaches are ineffective because no single executive could know enough about the highly complex projects that the company is considering. Moreover, even the most sophisticated quantitative approaches have limited value given that it is impossible for senior management to see the "quality of thinking" ${ }^{1}$ behind those valuations. As a result, project funding decisions were primarily driven by the advocacy skills of project champions. The following quote by one of the executives highlights quite vividly his perception regarding the lack of transparency in the evaluation process: "Figures don't lie, but liars can figure." (Sharpe and Keelin, 1998, p. 46). To capture these two key aspects of the decisionmaking process, we develop a game-theoretic model that combines moral hazard ex-ante (at the information acquisition stage) with adverse selection ex-post (at the information revelation stage).

Our study makes the following contributions to the existing literature. First, we show that different types of products require fundamentally different incentive structures. For novel products that are characterized by a less precise evaluation process, the firm should perfectly align a unit manager's compensation with the firm's overall performance. On the contrary, for products characterized by a more precise evaluation process, the firm should place a strong emphasis on individual incentives. Moreover, we find that more precise information leads to lower pay-performance sensitivity for both individual and shared incentives. As a result, the total wage of a product manager decreases as the precision of his information increases. The reason behind this counter-intuitive finding is that, more accurate information leads to a better alignment between the managers' and the firm's interests, thereby reducing the managers' information rents.

Second, we show that information asymmetries increase the effective cost of product evaluation, and therefore, for a wide range of parameters, the firm under-invests in information acquisition. Interestingly, for intermediate information acquisition costs and very precise information, the same information asymmetries lead the firm to over-invest in information. This result is driven by the firm's inability to distinguish informative signals from uninformative

\footnotetext{
${ }^{1}$ This term was used by one of the executives in Sharpe and Keelin (1998) to illustrate that senior managers could not rank these recommendations with respect to their rigor or robustness.
} 
ones when project managers possess private information. To circumvent these distortions in their product evaluation processes, many firms decide to outsource the product evaluation to external providers. Our analysis identifies the critical role of the relative advantage of the inhouse versus the external provider's evaluation precision in making this decision. In addition, we characterize the optimal evaluation policy for different information structures. Lastly, while a number of studies have looked at imperfect product evaluation and product portfolio decisions in isolation, it remains unclear how the presence of asymmetric information in the former stage would affect the latter. We find that the presence of asymmetric information results in an overly broad product portfolio scope, that is, the firm produces too many products, thereby spreading its resources too thinly.

\section{Literature Review}

The challenges associated with resource allocation processes have been central in the new product development (NPD) literature. A thorough review of this literature can be found in Kavadias and Chao (2007). Recently, an emerging stream has accounted for the potentially misaligned preferences in NPD processes (Terwiesch and Xu, 2008; Siemsen, 2008; Chao et al., 2009; Sommer and Loch, 2009; Mihm, 2010; Mihm et al., 2010; Xiao and Xu, 2012) and the reality that incentive mechanisms play a central role in such processes. The effect of incentive schemes on the effectiveness of resource allocation processes is more explicitly studied in Chao et al. (2009), Hutchison-Krupat and Kavadias (2013), and Chao et al. (2013). Chao et al. (2009) compare a policy in which a senior manager empowers the divisional manager to adapt the innovation budget to the divisional sales versus a policy in which the senior manager directly controls the division through a fixed budget. Hutchison-Krupat and Kavadias (2013) characterize optimal funding decisions across different resource allocation processes such as top-down, bottom-up, and strategic buckets. Lastly, Chao et al. (2013) study incentive schemes in a stage-gate process where senior management has to rely on a privately informed project manager in order to make go/no-go decisions. They emphasize the role of uncertainty regarding the quality of the project idea, and show how it might make an organization overly conservative in its project selection process, i.e., projects that would have been profitable do not get approved. We contribute in the above stream of resource allocation processes by capturing the dynamics arising when multiple product managers compete for the same resources. All of the aforementioned papers are concerned with the level of resources allocated to a single product, and as such, they do not address the challenges associated with managing a portfolio of projects.

Incentives for parallel innovation projects are studied in Ederer (2013). By combining both a theoretical and experimental analysis, he shows that when workers can freely learn the best practices from each other, the firm can only incentivize innovation by establishing shared incentives. This happens because individual pay-for-performance incentive schemes encourage imitation and free-riding on the successful ideas of others. While we also highlight the importance of shared incentives for an organization developing new products, our work differs from 
Ederer (2013) in several aspects. Most notably, in our setting the outcome of the product evaluation is not public information, and thus, the firm needs to incentivize the managers to reveal their information truthfully. Another recent stream of work in NPD has studied parallel search in the context of innovation tournaments (Terwiesch and Xu, 2008; Kornish and Ulrich, 2011; Boudreau et al., 2011), but the tradeoffs involved in these settings are considerably different than the resource allocation decisions within a single firm. As such, despite the extensive discussion in the NPD community about the necessity of running parallel projects (see Loch et al., 2006, and references therein) we know very little about how to manage such a process within the boundaries of the firm.

Our work also touches upon a central question in the capital budgeting literature in corporate finance. The stream most related to our setting begins with the seminal work of Stein (1997) which focuses on the role of corporate headquarters in allocating resources among competing projects. In particular, he compares the efficiency of internal capital markets with respect to the external ones. In a series of follow-up papers, Bernardo et al. (2001), Stein (2002), and Inderst and Laux (2005) examine the role of incentives in mitigating agency costs, and specifically, the potential private benefits that agents enjoy from controlling more capital, thereby reflecting a preference for "empire building".

Closer to our work, Friebel and Raith (2010) develop a model in which pay-for-performance incentives create an endogenous empire building motive, which in turn, might prevent a manager from truthfully communicating his private information. ${ }^{2}$ They also show that the firm can induce truthful communication by using shared incentives, albeit at the expense of additional information rents. Given these additional information rents, they examine whether the benefit of integration (namely, the pooling of resources) outweighs the cost of integration (the information rents), and they derive the conditions under which an integrated firm is more valuable than two separate firms. Our work differs from Friebel and Raith (2010) in several important ways. First, we are interested in the allocation of resources in innovation projects where the value of a project cannot be perfectly known before resources have been allocated to it. In contrast, in Friebel and Raith (2010) the value of a project is realized before the resource allocation stage. Second, we model the process of imperfect product evaluation, and as such, the managers in our model are incentivized to acquire information about the value of the product, rather than improve the quality of the product (as in Friebel and Raith (2010)). We find that the structure of the incentive scheme heavily depends on the characteristics of the information source (e.g., the information precision). Lastly, our model examines the effect of information asymmetry on the firm's product evaluation strategy, and in turn, on the firm's product portfolio scope. In contrast, in Friebel and Raith (2010), at equilibrium, resources are always allocated to the most profitable projects, so information asymmetries do not distort the firm's product portfolio.

In short, all of the above papers in the capital budgeting literature assume that information

\footnotetext{
${ }^{2}$ Recent theoretical literature has also examined the link between the incentive to exert effort and the incentive to share information in settings where agents work towards a common outcome (public good). For example, in Campbell et al. (2014) agents do not share information in order to maintain the motivation of their peers, but this leads to delays and even an over-production of ideas.
} 
regarding the type of the project is perfect and freely available to the agent, but not to the principal. On the contrary, in our setting, acquiring reliable information is associated with substantial costs incurred privately by the agent, and thus, the agent will only exert that effort if he is incentivized to do so. To the best of our knowledge, the only other paper that studies project selection when the agent is incentivized to acquire costly information is Lambert (1986). Importantly, Lambert (1986) considers a single-agent setting, and as such, his model does not address the issues that we discussed earlier regarding competition for resources among parallel projects.

\section{Model Setup}

Consider a firm that is faced with the decision of allocating its resources across multiple projects. The key decision for the firm is whether to choose a narrow product portfolio scope or a broader one. To capture this tradeoff in a mathematically tractable way, we assume that the firm is contemplating two projects, and we examine under what conditions the firm decides to allocate all of its resources in a single project (narrow scope) versus spreading them evenly across both projects (broad scope). The market value that the firm realizes from each project depends on two parameters: (i) the inherent market potential of each project, which is uncertain upfront and can be either good or bad; and (ii) the resources that the firm invests in the project. The firm seeks to maximize its profits by allocating resources to good projects and forgoing investments in bad ones.

A central element of our model is the product evaluation stage in which the firm can acquire costly information regarding each project's potential. This information is acquired through extensive experimentation by each project's respective product manager. Then, upon observing the outcome of this experimentation process, each product manager makes a recommendation to the senior management of the firm (from hereon, the firm), and the firm decides on the level of resources to allocate in each project. For example, in the case of GSK, the head of each R\&D unit (i.e., of each CEDD) would present a compound to the centralized Development Investment Board, and subsequently, the board members would decide about the progress of the compound in the next stage (the extremely resource-intensive Phase IIb). Similarly, at Wyeth there was a centralized Discovery Review Board that was responsible for making funding decisions across all therapeutic areas. As discussed extensively in the aforementioned examples, the "quality of thinking" behind such recommendations by the product managers is very hard to verify, and even less so to contract upon. As such, there can be considerable information asymmetry between the product managers and the firm.

In our setting, the presence of information asymmetry is reflected both in the "quality of thinking" as well as in the truthfulness of the recommendation that the product managers submit to the firm. We model the former by acknowledging that information acquisition (e.g., experimentation) is a costly process and can be done at various levels of quality (e.g., robustness checks may satisfy only some minimum standards, or may be very thorough). In particular, we 
assume that each product manager can choose between a high-effort and a low-effort evaluation process for his product. The chosen effort level is not observed by the firm because product evaluation critically relies on a manager's tacit information gathering and synthesis (e.g., the time managers spend meeting with people, trying to obtain their tacit knowledge, sitting in their offices trying to make sense of data, etc.). For the manager, high-effort evaluation comes with a private cost, while the cost of low-effort evaluation is normalized to zero. The latter form of information asymmetry aims to capture the fact that not all product managers truthfully communicate the results of their experimentation, especially when they compete for resources with one another. In short, our model incorporates ex-ante moral hazard (at the information acquisition stage) with ex-post adverse selection (at the recommendation stage), and as such, if the firm desires high-effort product evaluation and truthful recommendations, it has to design appropriate incentive schemes. Lastly, upon observing the managers' recommendation, the firm decides on its resource allocation strategy.

To summarize, the sequence of events is as follows (see Figure 1): (i) The firm announces the compensation scheme to the product managers; (ii) Each manager chooses his evaluation effort and incurs the associated private effort costs; (iii) Then, each manager observes a private and imperfect signal and makes a recommendation to the firm regarding his product's potential; (iv) Based on the managers' recommendations, the firm allocates resources to the products; (v) The products are launched and their market value is realized. The firm receives the corresponding payoffs and compensates its managers. In the following three subsections, we explain our modeling assumptions regarding the above stages in more detail.

Figure 1: Sequence of events.

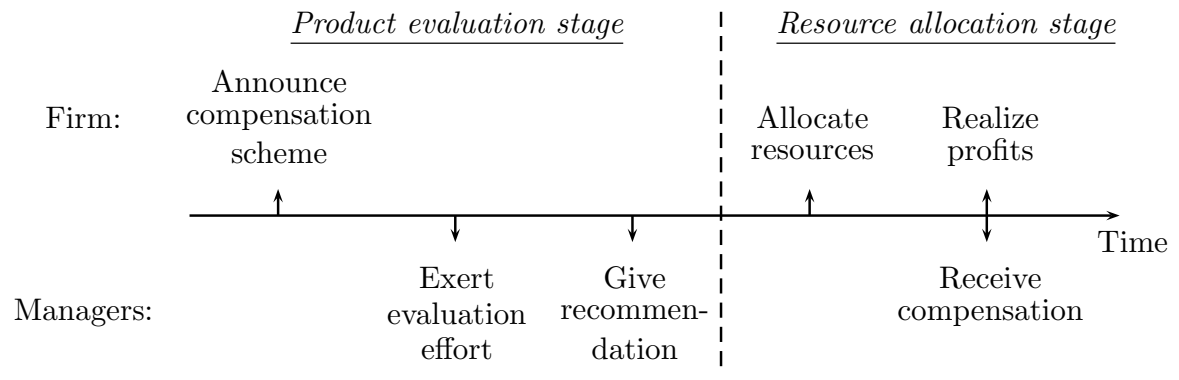

\section{The Product Evaluation Stage}

New projects carry significant uncertainty regarding their market potential. We capture this uncertainty by assuming that two ex-ante identical products $i$ and $j$ can either have high $\left(\theta_{i}=G\right)$ or low $\left(\theta_{i}=B\right)$ market potential. ${ }^{3}$ The true potential of each product is unknown to the firm and its managers, and both states are considered ex-ante equally likely. ${ }^{4}$ By evaluating his product, manager $i$ receives an imperfect signal $s_{i} \in\{g, b\}$ which indicates whether product

\footnotetext{
${ }^{3}$ For notational simplicity, we define explicitly only the parameters for project $i$. An identical set of parameters applies for product $j$ as well.

${ }^{4}$ This assumption is done for expositional clarity and does not affect qualitatively any of our results.
} 
$i$ has high $\left(s_{i}=g\right)$ or low $\left(s_{i}=b\right)$ market potential. In line with prior work on NPD (Loch et al., 2001; Thomke, 2007), we capture the informativeness of the signal for both products $i$ and $j$ by the parameter $q$ to which we refer to as signal precision. Mathematically, $q$ represents the conditional probability that the signal is reflective of the true market potential, i.e., $\operatorname{Pr}\left(s_{i}=\right.$ $\left.g \mid \theta_{i}=G\right)=\operatorname{Pr}\left(s_{i}=b \mid \theta_{i}=B\right)=q$. Importantly, the precision $q$ depends on the chosen effort level $e_{i}$ which can be high $\left(e_{i}=h\right)$ or low $\left(e_{i}=l\right)$. High-effort evaluation requires a cost $c>0$ which is privately incurred by the product manager, and results in a signal of precision $q \in\left(\frac{1}{2}, 1\right]$. In contrast, low effort is costless for the product manager, but results in an uninformative signal, i.e., $q=\frac{1}{2}$.

Upon observing the signal $s_{i}$, manager $i$ revises his prior belief for his product's market potential to account for the new information. In particular, since both states are ex-ante equally likely, the posterior beliefs are given by $\operatorname{Pr}\left(\theta_{i}=G \mid s_{i}=g\right)=\operatorname{Pr}\left(\theta_{i}=B \mid s_{i}=b\right)=q$. Then, manager $i$ submits his recommendation $m_{i} \in\{g, b\}$ about his product's potential to the firm. If $m_{i}=s_{i}$, then a manager truthfully reveals his signal. Thus, manager $i$ 's action space is fully characterized by his product evaluation effort, $e_{i}$, and his subsequent recommendation, $m_{i}$.

\section{The Resource Allocation Stage}

Once the firm receives the managers' recommendations, then it has to decide on whether to allocate all of its resources to a single product or split them evenly between products $i$ and $j$. The market value to the firm generated by product $i$, denoted by $\nu_{i}$, depends on both, its inherent potential $\theta_{i}$ as well as the amount of resources invested in it. The notation we use to capture this dependency is summarized in Table 1.

Table 1: A product's market value.

\begin{tabular}{lccc}
\hline & No resources & Partial funding & All resources \\
\hline Good product $\left(\theta_{i}=G\right)$ & 0 & $v_{1}$ & $v_{2}$ \\
\hline Bad product $\left(\theta_{i}=B\right)$ & 0 & $z_{1}$ & $z_{2}$ \\
\hline
\end{tabular}

More specifically, we assume that a product that does not receive any resources for development always generates zero market value, regardless of whether it has a good $\left(\theta_{i}=G\right)$ or bad $\left(\theta_{i}=B\right)$ market potential. In contrast, for products that receive resources, their generated value increases as more resources are allocated to them because more resources improve a product's quality, and thus, its market value. Resources create more value when they are allocated to products with good market potential. In particular, if the firm splits resources evenly across two products, then each bad product's market value is $z_{1} \geq 0$, whereas each good product's market value is $v_{1}>z_{1}$. If the firm allocates all the resources to a bad product, then this product's market value is $z_{2}>z_{1}$, and the corresponding value for a good product is $v_{2}>\max \left\{v_{1}, z_{2}\right\}$. In short, the above assumptions imply that the firm prefers to allocate its resources to good rather than bad products, and that more resources lead to products of higher value.

Note that the choice of product portfolio scope becomes a trivial question either if the firm realizes increasing returns $\left(v_{2}>2 v_{1}, z_{2}>2 z_{1}\right)$, or if there is no value in identifying good 
projects $\left(v_{2}<v_{1}+z_{1}\right)$. In the former case, it is always optimal to allocate all resources to a single project, while in the latter case, the firm always prefers to split resources evenly between the two projects. Therefore, in the remainder of this paper, we analyze the more interesting situation where the marginal value of investing more resources in a product is decreasing, $v_{2}<2 v_{1}$ and $z_{2}<2 z_{1}$, and where "winner-picking" is valuable for the firm, $v_{2}>v_{1}+z_{1}$. This implies that all else being equal, splitting resources evenly between two good (bad) products yields higher profits than allocating all resources into a single good (bad) product. This assumption is also in line with recent empirical work that shows that firms with a broader product portfolio scope experience higher performance (Klingebiel and Rammer, 2014). Lastly, for clarity of exposition, we focus on cases where the marginal value of having a second product is smaller for bad products than for good products, i.e., $2 z_{1}-z_{2}<2 v_{1}-v_{2}$. In other words, when products are bad, the decision of whether to split resources or allocate all of them in one product, is relatively inconsequential for the firm compared to the case of good products where the stakes are much higher. This implies that shifting resources is more critical for good rather than bad products.

\section{The Compensation Scheme}

As discussed in our motivating examples, companies often struggle to strike a balance between individual incentives (e.g., rewarding a specific CEDD for its performance in the case of GSK) and shared incentives (e.g., as in Wyeth where divisions were rewarded based on the R\&D performance of the entire organization). While the former is typical in agency relationships and requires little justification, our model also illustrates why, in many settings, the latter might be equally important. In particular, it can be readily seen that, if a manager's payoff depends only on the performance of his own product, then the manager is always better off by communicating a positive recommendation for his product, so that he receives more resources from the firm. Thus, information becomes unreliable, and therefore, irrelevant for the resource allocation decisions of the firm. However, once shared incentives are included in the compensation scheme, a manager who observes a bad signal, and anticipates that his product is likely to fail, becomes more likely to "step aside" and allow his peer's product to receive more resources.

In line with prior literature on shared incentives (Rotemberg and Saloner, 1994; Siemsen et al., 2007; Friebel and Raith, 2010), we focus on compensation schemes of the following structure: $\hat{w}_{i}=k_{0}+k_{s} \nu_{i}+k_{p} \nu_{j}$, where $k_{0}$ is a fixed wage, $k_{s}$ is the self-product sensitivity that determines the manager's share from the performance of his own product, and $k_{p}$ is the respective peer-product sensitivity. ${ }^{5}$ We refer to $k_{s}$ as "individual incentive", and to $k_{p}$ as "shared incentive". Our compensation scheme is mathematically equivalent to $\hat{w}_{i}=k_{0}+\left(k_{s}-\right.$ $\left.k_{p}\right) \nu_{i}+k_{p}\left(\nu_{i}+\nu_{j}\right)$. Intuitively, $\left(k_{s}-k_{p}\right)$ determines the share that each manager receives from his own product's value, and $k_{p}$ determines the share that the managers receive from the firm's overall performance. Consistent with the aforementioned papers, we restrict attention to linear

\footnotetext{
${ }^{5}$ Where appropriate, we use the notation $\hat{x}$ to denote a random variable, and distinguish it from its expected value which, for notational convenience, we denote by $\mathrm{x}$.
} 
compensation contracts that are symmetric between the two agents. ${ }^{6}$

We employ a linear compensation scheme for three reasons. First, under fairly general conditions, Holmstrom and Milgrom (1987) have shown that optimal compensation schemes are linear in the aggregated outcome when agents influence outcomes through a series of actions. Based on this fundamental result, linear compensation schemes have become pervasive in the academic literature when studying, e.g., incentive design (Siemsen et al., 2007), relative performance evaluation (Aggarwal and Samwick, 1999), or optimal organizational forms (Friebel and Raith, 2010). Second, contract linearity allows us to derive analytical results in a complex setting that combines ex-ante moral hazard with ex-post adverse selection, and facilitates the required mathematical exposition. Lastly, linear schemes are intuitive and easily implementable, and thus, widely found in practice. For example, at Wyeth employees received shares of an overall bonus pool.

Given the compensation $\hat{w}_{i}$, manager $i$ 's utility $\hat{U}_{i}$ is comprised of $\hat{w}_{i}$ net his effort cost, i.e., $\hat{U}_{i}=\hat{w}_{i}-c I_{\left\{e_{i}=h\right\}}$, where $I_{\{A\}}$ is the indicator function of event $A$. Following a typical assumption in the principal-agent literature, we assume that managers have limited liability, i.e., $\hat{w}_{i} \geq 0$, and that they are risk-neutral. Finally, the firm's profit is the sum of the products' market value minus the managers' compensation, which is $\hat{\Pi}(k)=\sum_{i} \nu_{i}-\hat{w}_{i}=\left(1-k_{s}-k_{p}\right)\left(\nu_{i}+\right.$ $\left.\nu_{j}\right)-2 k_{0}$. For ease of exposition, we refer to manager $i$ 's expected wage and utility, and the firm's expected profit by $w_{i}, U_{i}$, and $\Pi$, respectively, where the expectation is taken over the products' market potential, $\theta$.

\section{Analysis}

In this section we characterize the firm's optimal product evaluation and resource allocation strategy. To ensure that the derived equilibrium solution is subgame perfect, we solve our model by backwards induction. Therefore, we first determine the firm's optimal resource allocation policy for any given outcome of the product evaluation stage (section 4.1). Then, we examine the incentive schemes that the firm can use to induce the desired level of product evaluation by the product managers (section 4.2). Finally, we characterize the optimal product evaluation strategy (section 4.3) accounting for the fact that different product evaluation strategies require different incentive schemes.

\footnotetext{
${ }^{6}$ Our focus on symmetric contracts is based on the theory of equity (Adams, 1963). In the words of Akerlof and Yellen (1988, p.45): "All textbooks consider it self-evident that the most important aspect of a compensation system is its accordance with workers' conceptions of equity". A more detailed discussion about the numerous studies that provide support for this theory can be found in Akerlof and Yellen (1990), Fehr and Schmidt (1999), and Bolton and Ockenfels (2000). In our setting, given that managers are ex-ante identical, an asymmetric contract would be hard to put in place without the firm suffering severe repercussions from the managers' sense of unfairness. As such, in the remainder of our analysis we assume a symmetric contract structure. It is worth noting though, that our characterization of the optimal product evaluation strategy holds for asymmetric contract structures as well (the analysis is available upon request from the authors).
} 


\subsection{The Optimal Resource Allocation Strategy}

Once the firm receives the recommendations of the two managers, it decides on the amount of resources to allocate to each product. Clearly, when the managers do not report truthfully their signals, their recommendations are not informative to the firm, and the firm allocates the resources based on its prior beliefs. That is, resources are evenly split across the two products. When the managers report truthfully their signals, the firm needs to consider three different cases for the evaluation stage: (i) both managers exert low effort, $e=(l, l)$; (ii) manager $i$ exerts high effort, while manager $j$ exerts low effort, $e=(h, l)$; and (iii) both managers exert high effort, $e=(h, h){ }^{7}$ The optimal resource allocation strategy maps the managers' product evaluation strategy $e=\left(e_{i}, e_{j}\right)$ together with the received recommendations $m=\left(m_{i}, m_{j}\right)$ into the resource allocation that maximizes expected profits. Note that, as we show in the next section, through the design of an appropriate contract, the firm can always anticipate the evaluation strategy of its managers and whether or not they report truthfully their signals. Lemma 1 fully characterizes the firm's optimal resource allocation strategy. For brevity and expositional clarity, all proofs are in the Appendix.

Lemma 1 (The Optimal Resource Allocation). Define $q_{0} \equiv\left(v_{1}+z_{1}-z_{2}\right) /\left(v_{2}-z_{2}\right)$, $q_{g} \equiv\left(v_{1}+3 z_{1}-2 z_{2}\right) / 2\left(v_{2}-v_{1}-z_{2}+z_{1}\right), q_{b} \equiv\left(3 v_{1}-v_{2}+z_{1}-z_{2}\right) / 2\left(v_{1}-z_{1}\right)$, and note that $\frac{1}{2}<q_{b}<q_{g}$. Then, for a given evaluation strategy $e$, a signal precision $q$, and received recommendations $m$, the firm's optimal resource allocation is summarized in Table 2, where "-" indicates that the result holds for any possible realization of the respective parameter.

Table 2: The optimal resource allocation.

\begin{tabular}{|c|c|c|c|}
\hline $\begin{array}{c}\text { Evaluation efforts } \\
e=\left(e_{i}, e_{j}\right)\end{array}$ & $\begin{array}{l}\text { Signal precision } \\
q\end{array}$ & $\begin{array}{l}\text { Received recommendations } \\
\quad m=\left(m_{i}, m_{j}\right)\end{array}$ & $\begin{array}{c}\text { Optimal resource } \\
\text { allocation }\end{array}$ \\
\hline$(l, l)$ & - & - & split evenly \\
\hline \multirow{3}{*}{$(h, l)$} & $q<q_{b}$ & - & split evenly \\
\hline & $q_{b} \leq q<q_{g}$ & $\begin{array}{l}(g,-) \\
(b,-)\end{array}$ & $\begin{array}{l}\text { split evenly } \\
\text { all to product } j\end{array}$ \\
\hline & $q_{g} \leq q$ & $\begin{array}{l}(g,-) \\
(b,-)\end{array}$ & $\begin{array}{l}\text { all to product } i \\
\text { all to product } j\end{array}$ \\
\hline \multirow{3}{*}{$(h, h)$} & $q \leq q_{0}$ & - & split evenly \\
\hline & \multirow[b]{2}{*}{$q>q_{0}$} & $(g, b)$ & all to product $i$ \\
\hline & & $\begin{array}{l}(g, g) \\
(b, b)\end{array}$ & split evenly \\
\hline
\end{tabular}

Lemma 1 presents some intuitive properties of the firm's optimal resource allocation strategy. First, when both managers exert low effort, the firm does not receive any useful information, so it decides to split resources evenly across the two products. In the case where only manager $i$ pursues a high-effort product evaluation, the firm will only direct all of its resource to the most

\footnotetext{
${ }^{7}$ Throughout, we adopt the convention that in case of asymmetric effort levels, manager $i$ always exerts high effort, while manager $j$ exerts low effort.
} 
promising product, if the information precision is high enough. Otherwise, if $q<q_{g}\left(q<q_{b}\right)$, then the good (bad) signal for product $i$ is discarded, and resources are still split evenly. The last case also highlights the substitution effect between the two products: even if there is no high-effort recommendation for the product at hand (in this case product $j$ ), it might still be optimal to invest all resources into it as long as there is reliable information that product $i$ is of low market potential. Lastly, when both managers exert high effort, the optimal resource allocation depends on both managers' recommendations. If the two managers give identical recommendations, then, again, an equal split of the resources is the preferable choice. If, on the other hand, the recommendations are different, then all resources should be directed to the most promising product.

\subsection{Product Evaluation under Asymmetric Information}

In the previous section, we characterized the optimal resource allocation strategy, given that the managers report truthfully their signals. Recall that, given the information asymmetry between the managers and the firm, such truthful reporting cannot be taken for granted, but rather, it has to be induced through an appropriate incentive scheme. In this section, we derive the optimal contract that allows the firm to induce high-effort evaluation and truthful reporting (Proposition 2), and discuss how our key contextual parameters affect the balance between individual and shared incentives. To establish a benchmark for our subsequent discussion and to illustrate the key tradeoffs of the firm's operating environment, we begin with the first-best product evaluation strategy in which the managers and the firm act as one entity.

\section{The First-Best Benchmark}

Without any incentive misalignment between the product managers and the firm, the firm does not need to pay any bonus $k_{s}$ or $k_{p}$ to motivate the managers to exert high effort and to truthfully reveal their information. The firm simply reimburses the product managers for their effort costs by paying a fixed wage $k_{0}=c$. Hence, without any information asymmetry, the firm's optimal product evaluation strategy solves $e^{F B}=\arg \max _{e} \Pi^{F B}(e)$, where $\Pi^{F B}(e)=$ $\mathbb{E}_{\theta}\left[\nu_{i}+\nu_{j} \mid e\right]-c\left(I_{\left\{e_{i}=h\right\}}+I_{\left\{e_{j}=h\right\}}\right)$ denotes the firm's ex-ante expected profit under the evaluation strategy $e$.

Proposition 1 (First-Best Product Evaluation). Let $q_{c} \equiv\left(3 v_{1}-v_{2}+3 z_{1}-2 z_{2}\right) /\left(v_{2}-z_{2}\right)$, and define $\zeta_{1} \equiv \frac{1}{4}\left(q v_{2}-v_{1}+(1-q) z_{2}-z_{1}\right), \zeta_{2} \equiv \frac{1}{4}\left(2\left(v_{1}+z_{1}\right)-\left(v_{2}+z_{2}\right)\right)$, and $\zeta_{3} \equiv 2 \zeta_{1}-\zeta_{2}$. The firm's first-best product evaluation strategy is as follows:

(i) If $q<q_{c}$, then, $e^{F B}=(h, h)$ for $c \leq \zeta_{1}$; and $e^{F B}=(l, l)$ elsewhere.

(ii) If $q \geq q_{c}$, then, $e^{F B}=(h, h)$ for $c \leq \zeta_{2} ; e^{F B}=(h, l)$ for $\zeta_{2}<c \leq \zeta_{3}$; and $e^{F B}=(l, l)$ elsewhere.

Figure 2 illustrates the key properties of the first-best evaluation strategy. Firstly, as we would intuitively expect, high-effort evaluation is undertaken only when the information precision is sufficiently high, $q>q_{0}$, and the evaluation cost sufficiently low, $c \leq \max \left\{\zeta_{1}, \zeta_{3}\right\}$. 
Figure 2: The firm's first-best product evaluation strategy.

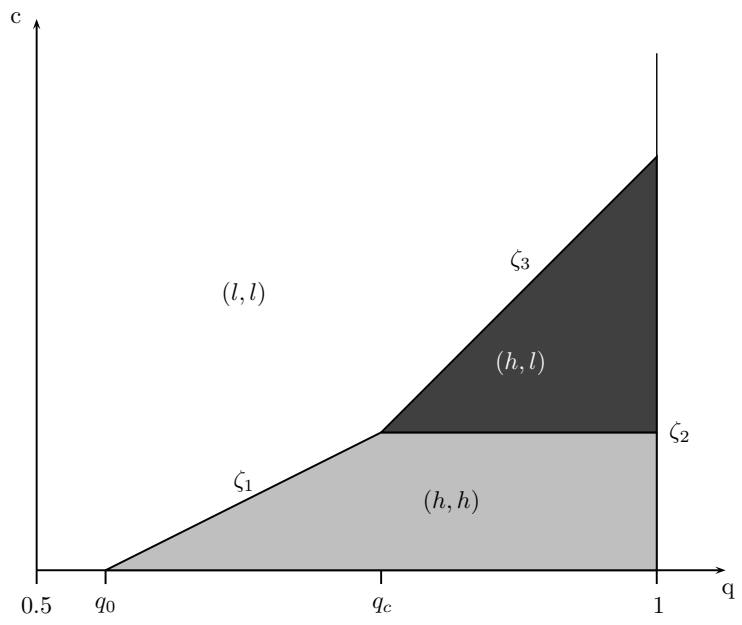

The firm's first-best product evaluation is (i) $e^{F B}=(h, h)$ in the light gray region; (ii) $e^{F B}=(h, l)$ in the dark gray region; and (iii) $e^{F B}=(l, l)$ in the white area.

Otherwise, the value of information does not justify its cost, and the firm decides to forgo the rather inefficient evaluation process. Remarkably, even if the evaluation cost is zero, the firm never exerts high-effort product evaluation if $q \leq q_{0}$. In this case, the information precision is so low that the outcome of the product evaluation would not affect the firm's resource allocation policy. As such, the value of information is zero, and the firm does not undertake product evaluation despite the negligible cost of doing so.

Secondly, for moderate $q$ values $\left(q_{0}<q<q_{c}\right)$, the firm adopts a rather coarse evaluation strategy by either exerting high effort for both products or none. However, for higher $q$ values $\left(q \geq q_{c}\right)$ and moderate $\operatorname{costs} c\left(\zeta_{2}<c \leq \zeta_{3}\right)$, the firm finds it optimal to pursue high-effort evaluation for only one of its products. Thus, even if the information is perfect $(q=1)$, the firm should not evaluate both products unless the cost is sufficiently low $\left(c<\zeta_{2}\right)$. Moreover, if a product's market value is relatively insensitive to the allocated resources, i.e., $v_{2}<\frac{3}{2}\left(v_{1}+z_{1}\right)$, then the asymmetric effort strategy, $e=(h, l)$, is never optimal (i.e., $q_{c}>1$ ). On the contrary, if the market value is very sensitive to the invested resources $\left(v_{2} \approx 2 v_{1}\right)$, then pursuing high-effort for only a single product is optimal for a wide range of parameters (as $q_{c}$ approaches $\frac{1}{2}$ ).

\section{Incentives for Product Evaluation}

In this section, we account for the key challenge that motivated our study: the highly specialized and complex nature of pharmaceutical $R \& D$ projects gives rise to information asymmetries between the managers and the firm. As such, to elicit the necessary information for an efficient resource allocation, the firm needs to design appropriate incentive schemes. As discussed earlier, managers can pursue three different evaluation strategies. The firm can induce each one of the evaluation strategies by offering an appropriate incentive scheme. Essentially, the firm has to balance the benefits from a specific product evaluation strategy, with the direct (i.e., wages) 
and indirect (i.e., information rents) costs associated with it.

By the revelation principle, the search for an optimal incentive scheme can, without loss of generality, be restricted to contracts that induce truthful reporting by the managers. Intuitively, non-truth-telling contracts provide no value to the firm, and therefore, the firm would never reward a manager for providing inconsequential information. Moreover, the next Lemma states that a contract that incentivizes only one product manager to exert high-effort evaluation can never be incentive compatible. Intuitively, given ex-ante identical managers, if the contract terms are such that one of the managers decides to exert high effort, so does the other.

Lemma 2 (Symmetric EFForT). No symmetric compensation scheme exists such that, in equilibrium, managers are truth-telling and choose different effort levels during product evaluation.

By Lemma 2, to find the firm's optimal product evaluation strategy, we only need to investigate the firm's optimal contract that induces truth-telling and high effort by either both managers or neither. Consider first the simpler case where the firm incentivizes both managers to pursue a low-effort evaluation strategy. In that case, the optimal contract is $k_{0}=k_{s}=k_{p}=0$. This contract is clearly incentive compatible in effort because no manager has an incentive to exert high effort, since then he would incur a cost without receiving any reward. In short, the firm can induce low-effort product evaluation by simply offering no reward to its managers, and in that case, the firm optimally splits resources evenly across products (since $v_{2}<2 v_{1}$ and $\left.z_{2}<2 z_{1}\right)$ to obtain an expected profit $\Pi(k=0)=v_{1}+z_{1}$.

We now examine the more interesting case where the firm incentivizes both managers to exert high-effort evaluation and to truthfully report their signals. In that case, the firm's objective is to maximize the expected value of both products net the managers' wages. More formally, the firm solves the following optimization problem (the detailed derivation can be found in the proof of Lemma 3):

$$
\begin{aligned}
\max _{k_{0}, k_{s}, k_{p}} & \Pi(k)=\left(1-k_{s}-k_{p}\right) \frac{1}{2}\left(q v_{2}+v_{1}+(1-q) z_{2}+z_{1}\right)-2 k_{0} \\
\text { s.t. } & k_{s}\left(q v_{2}+(1-q) z_{2}\right)+k_{p}\left(q v_{1}+(1-q) z_{1}\right) \geq k_{p}\left(q v_{2}+(1-q) z_{2}\right)+k_{p}\left((1-q) v_{1}+q z_{1}\right) \\
& k_{p}\left(q v_{2}+(1-q) z_{2}\right)+k_{p}\left((1-q) v_{1}+q z_{1}\right) \geq k_{s}\left((1-q) v_{2}+q z_{2}\right)+k_{p}\left(q v_{1}+(1-q) z_{1}\right) \\
& 2 k_{s}\left(q v_{2}+(1-q) z_{2}\right)-8 c \geq k_{s}\left(v_{2}+z_{2}\right) \\
& k_{0}+k_{s} z_{2} \geq 0, \quad k_{0}+k_{p} z_{2} \geq 0 .
\end{aligned}
$$

Constraints (IC-g) and (IC-b) ensure that both managers truthfully reveal a good and a bad signal, respectively. These constraints are necessary to address the adverse selection problem at the recommendation stage. Similarly, the moral hazard problem at the product evaluation stage is addressed by constraint (IC-e) that ensures that managers are better off exerting high-effort product evaluation. Lastly, the limited liability constraints (LL) guarantee 
that managers' wages are non-negative. Before we analyze the combined case of moral hazard and adverse selection described above, it is instructive to disentangle the effect of each source of information asymmetry on the design of the incentive scheme.

First, consider the case where only adverse selection is present. In this case, the managers' efforts are observable and the firm can contract directly on them. Mathematically, the firm solves the optimization problem outlined above, but without constraint (IC-e). Then, it is optimal for the firm to just reimburse each manager for his effort costs by paying a fixed wage $k_{0}=c$. Moreover, since each manager receives a fixed wage, independent of the realization of his project value, managers have no incentive to misrepresent their signals. In other words, no additional bonus payments are necessary to persuade a manager to truthfully reveal his private signal. Hence, under observable effort, regardless of whether the signals are public or private, the firm realizes first-best profits.

We now consider the case where only moral hazard is present. In this case, the managers' efforts are unobservable but their signals are public. Mathematically, the firm solves the optimization problem outlined above, but without constraints (IC-g) and (IC-b). Interestingly, according to Lemma 3, public signals are not sufficient to mitigate the incentive misalignment between the managers and the firm, and as such, the firm cannot realize first-best profits.

Lemma 3 (Optimal Contract under Pure Moral Hazard). Let $q_{d} \equiv\left(3 z_{2}-z_{1}-v_{1}\right) /\left(v_{2}-\right.$ $\left.z_{2}\right)$. With public signals, the optimal contract that induces high-effort product evaluation by both managers is:

(i) If $q<q_{d}$, then $k_{s}=k_{p}=\frac{8 c}{(2 q-1)\left(v_{2}-z_{2}\right)}$, and $k_{0}=-k_{p} z_{2}$.

(ii) If $q \geq q_{d}$, then $k_{s}=\frac{8 c}{(2 q-1)\left(v_{2}-z_{2}\right)}, k_{0}=k_{p}=0$.

Lemma 3 reveals that the structure of the optimal contract critically depends on the value of the information precision. Note that, under pure moral hazard, the only purpose served by the contract is to induce high-effort product evaluation. Specifically, the primary lever that the firm uses to induce effort is the individual incentive, $k_{s}$. A higher $k_{s}$ makes the manager more inclined to request resources for his project, and therefore, more willing to acquire information that indicates the potential of his project.

When the information precision is high $\left(q \geq q_{d}\right)$, it is optimal for the firm to induce high effort by emphasizing only the individual performance incentives $\left(k_{s}>0\right)$, while keeping both the fixed wage, $k_{0}$, and the shared incentives, $k_{p}$, to zero. This happens because, when $q$ is high, information is more valuable both for the manager and the firm. From the manager's perspective, information of higher precision not only allows the manager to demonstrate the superiority of his product more clearly, but it also means that, conditioning on a good signal, his product is more likely to succeed. As a result, inducing high-effort evaluation becomes "cheaper" for the firm which can lower the manager's share, $k_{s}$, and still satisfy the manager's incentive compatibility constraint. On the contrary, when the information precision is low $\left(q<q_{d}\right)$, exerting high effort is less promising for the manager, and therefore more expensive for the firm which has to commit to a relatively high $k_{s}\left(k_{s}\right.$ decreases in $q$ ). To offset this high 
bonus payment, the firm introduces the negative fixed wage $k_{0}<0$ through which the firm extracts the manager's information rents.

One might wonder why the firm needs to introduce shared incentives in a setting where signals are public, and therefore, the managers need not be incentivized to reveal them truthfully. Interestingly, the sole purpose of shared incentives in this case is to allow the firm to introduce a negative fixed wage without violating the managers' limited liability constraints. Intuitively, when a manager incurs the fixed wage upfront, and receives a bad signal, all the resources are allocated to his peer's project. Then, unless he receives a share from his peer's project value $\left(k_{p}>0\right)$, the manager ends up with a negative wage. In fact, because ex-ante, the likelihood of a good and a bad signal are equal to each other, so are the sensitivity parameters $k_{s}$ and $k_{p}$. In short, the firm perfectly aligns the managers' compensation with the overall firm performance, without offering an additional reward for individual over peer performance. Having discussed the role of adverse selection and moral hazard separately, we are now ready to analyze the optimal contract when both are present.

Proposition 2 (Optimal Contract under Moral Hazard and Adverse Selection). The optimal contract that induces truth-telling and high-effort product evaluation by both managers is:

(i) If $q<q_{d}$, then $k_{s}^{*}=k_{p}^{*}=\frac{8 c}{(2 q-1)\left(v_{2}-z_{2}\right)}$, and $k_{0}=-k_{p}^{*} z_{2}$.

(ii) If $q \geq q_{d}$, then $k_{s}^{*}=\frac{8 c}{(2 q-1)\left(v_{2}-z_{2}\right)}, k_{p}^{*}=\frac{(1-q) v_{2}+q z_{2}}{q\left(v_{2}-v_{1}\right)+(1-q) v_{1}+(1-q)\left(z_{2}-z_{1}\right)+q z_{1}} \cdot k_{s}^{*}$, and $k_{0}^{*}=-k_{p}^{*} z_{2}$.

The first noteworthy result of Proposition 2 is that for $q<q_{d}$, the optimal contract is identical to the contract described under pure moral hazard (Lemma 3). In other words, in low information precision environments, the presence of adverse selection does not affect the optimal contract. The striking similarity of the two contracts can be explained as follows. Mathematically, accounting for adverse selection in addition to moral hazard, implies that we need to include constraints (IC-g) and (IC-b) in the optimization problem solved in Lemma 3. Recall, from the discussion in Lemma 3, that the optimal contract for $q<q_{d}$, is such that a manager's compensation is perfectly aligned with the firm's overall performance as the manager is equally rewarded for the success of his project as he is for the success of his peer's (i.e., $k_{s}^{*}=k_{p}^{*}$ ). As such, the manager has no incentive to misreport his signal, and it can be easily verified that constraints (IC-g) and (IC-b) are always satisfied. Hence, for $q<q_{d}$ the optimal contract remains the same as in the corresponding part of Lemma 3. In the remainder of this section, we focus on the second part of Proposition 2.

For $q \geq q_{d}$, the structure of the optimal contract is fundamentally different than the corresponding part of Lemma 3. In this case, the firm no longer focuses entirely on individual incentives, but introduces shared incentives aimed specifically at inducing truth-telling among the competing managers. ${ }^{8}$ At optimality, the firm needs to pay just enough to induce truthtelling by a manager with a bad signal, i.e., constraint (IC-b) is binding. Since it is more

\footnotetext{
${ }^{8}$ Recall that for $q<q_{d}$, the role of shared incentives were to satisfy the limited liability constraints rather than induce truth-telling.
} 
expensive to motivate a manager to reveal his bad signal than his good signal, constraint (IC-g) is always non-binding. It is also noteworthy that the addition of adverse selection does not affect the share of individual incentives, $k_{s}^{*}$, as the latter is determined entirely by constraint (IC-e), which at optimality is always binding, and importantly, independent of $k_{p}^{*}$. Put differently, the presence of adverse selection, even though it changes the structure of the optimal contract, it does not interfere with the effort incentives (moral hazard). Interestingly, the reverse is not true, as the presence of moral hazard affects the contract terms that address adverse selection, namely, $k_{p}^{*}$ depends on $k_{s}^{*}$. Graphically, this is illustrated in Figure 3 in which the optimal contract is determined by the intersection of constraints (IC-e) and (IC-b). Lastly, $k_{0}$ is always set so that the second limited liability constraint is binding.

Figure 3: The firm's optimization problem.

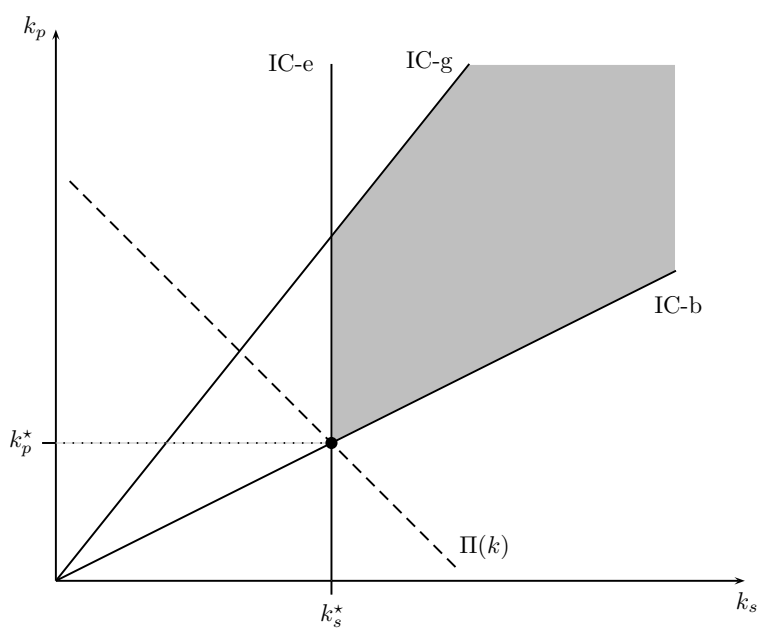

The light gray region indicates the set of all feasible contracts that induce truth-telling and high effort for given $k_{0}$ and $q \geq q_{d}$. The optimal bonus payment $\left(k_{s}^{*}, k_{p}^{*}\right)$ is at the intersection of (IC-b) and (IC-e).

\section{Balancing Individual versus Shared Incentives}

Having characterized the structure of the optimal contract, we now explore how the balance between individual and shared incentives changes with respect to our key parameters. First, with simple algebraic manipulation it can be readily seen that both $k_{s}^{*}$ and $k_{p}^{*}$ decrease in $q$. In other words, managers who can acquire better information receive a smaller share of each product's value. This counter-intuitive finding can be explained as follows. Recall that $k_{s}^{*}$ is entirely determined by constraint (IC-e). From (IC-e) we see that as the precision, $q$, increases, all else being equal, exerting high effort becomes more rewarding for the manager than exerting low effort. This happens because the only reason for the manager to exert high effort is so that he can credibly indicate the product's high potential to the firm, and therefore, request more resources for it. Clearly, the credibility of the manager's recommendation, and thus, his incentive to exert high effort in the first place increase as the information precision increases. As such, a higher information precision makes higher effort more rewarding for the manager. 
At the same time, the firm realizes that it can now lower the manager's share of his project value, $k_{s}^{*}$, while still ensuring that his effort incentive constraint (IC-e) is satisfied. That is why $k_{s}^{*}$ decreases in $q$.

To see why $k_{p}^{*}$ decreases in $q$, recall that the reason why a manager with a bad signal might report a good signal is that he can request more resources for his project. These resources, however, are only beneficial to the manager if his project eventually succeeds in the market. As the information precision increases, and given that the manager has observed a bad signal, the likelihood that his project will "defy the odds", and turn into a success, is shrinking. As a result, lying to the firm becomes less rewarding, and all else being equal, the firm can incentivize truth-telling with a lower $k_{p}^{*}$. Intuitively, managers with a high evaluation precision are likely to truthfully report their signals, as there is little value in claiming resources for a project that is bound to fail. It is worth noting the stark contrast regarding the effect of a noisier environment on the pay-performance sensitivities (i.e., $k_{s}^{*}$ and $k_{p}^{*}$ ) between our model and the standard theory on principal-agent models. For instance, in his seminal work Holmstrom (1979) shows that the pay-performance sensitivity increases as the effort has more influence on the final outcome, i.e., as the environment becomes less noisy. This comparison highlights the fundamentally different nature of incentives that induce higher effort for information acquisition versus moral hazard settings where an agent's effort stochastically improves the outcome of the project.

Second, both $k_{s}^{*}$ and $k_{p}^{*}$ decrease as $v_{2}$ increases, i.e., when allocating all the resources to a single project becomes more rewarding. The former happens because a higher $v_{2}$ makes exerting effort more rewarding for the manager: if his project receives the entire resource budget, its market value will be much higher, and so will his share of that value. The latter happens because a higher $v_{2}$ makes the manager more willing to disclose a bad signal truthfully: if his peer's product succeeds, he will also receive a share from that high value project. Thus, as $v_{2}$ increases, the firm need not pay as high $k_{s}^{*}$ and $k_{p}^{*}$ to incentivize the managers to exert high-effort and report truthfully. Interestingly, $k_{s}^{*}$ is invariant in $v_{1}$ while $k_{p}^{*}$ increases in $v_{1}$. A higher $v_{1}$ erodes the value from ex-post "winner-picking", and therefore, it has the exact opposite effect of $v_{2}$ when it comes to incentivizing truth-telling. It has no effect, however, when it comes to incentivizing high effort ex-ante, as due to symmetry the manager might still receive $v_{1}$ in either case (i.e., under high or low effort).

Corollary 1 (Individual vs. Shared Incentives). For $q \geq q_{d}, \frac{k_{p}^{*}}{k_{s}^{*}}<1$ and the ratio decreases in $q$ and $v_{2}$, while it is invariant in $c$.

By Corollary 1 , the ratio of $k_{p}^{*}$ to $k_{s}^{*}$ decreases in both $q$ and $v_{2}$, but it is invariant in $c$. Figure 3 illustrates how $k_{s}^{*}$ ensures high-effort evaluation, while the ratio $\frac{k_{p}^{*}}{k_{s}^{*}}$ ensures truthtelling. To see why the cost $c$ does not affect a manager's truth-telling propensity, note that each manager decides on his recommendation after incurring the effort cost. Hence, effort costs are sunk costs and do not affect a manager's recommendation. To see why $k_{p}^{*}$ is decreasing more steeply in $q$ than $k_{s}^{*}$, note that information of higher precision is always more crucial ex-post (i.e., when a bad signal has actually been realized) than ex-ante (i.e., when either a good or a bad signal can be realized). More specifically, a higher precision raises the manager's 
payoff if a good signal is realized, but lowers his payoff if a bad signal is realized. Due to this uncertainty, $k_{s}^{*}$ is only moderately decreasing in $q$. In contrast, when the manager decides whether to truthfully report his bad signal, $q$ has a direct detrimental effect on the value of his project. Therefore, $k_{p}^{*}$ is more sensitive to the manager's information precision.

This result bears important managerial implications for the optimal balance between individual and shared incentives. It states that in environments of higher information precision (high $q$ ) or where "winner-picking" is more crucial (high $v_{2}$ ), the firm needs to shift its focus towards rewarding based on the performance of individual project units rather than on company-wide metrics. So far, our discussion was focused on the pay-performance sensitivities $k_{s}^{*}$ and $k_{p}^{*}$. One might think that even though $k_{s}^{*}$ and $k_{p}^{*}$ decrease in $q$ and increase in $c$, the total utility of a manager might increase in the precision of his information and decrease in his effort costs. Rather surprisingly, Proposition 3 shows that this is not the case.

Proposition 3 (Information Rents). A manager's expected utility $U_{i}\left(k^{*}\right)$ decreases in $q$ and $v_{2}$, and increases in $c$; while the firm's expected profit $\Pi\left(k^{*}\right)$ increases in $q$ and $v_{2}$, and decreases in $c$.

Proposition 3 states a counter-intuitive result: a manager's utility decreases in the information precision of the evaluation process, that is, when the manager can provide better information to the firm. Similarly, when this information becomes more important (i.e., $v_{2}$ increases), the manager's utility decreases as well. Thus, even though a higher $q$ and higher $v_{2}$ raise the expected value of each product, the drop in $k_{s}^{*}$ and $k_{p}^{*}$ is so steep that it leaves each manager with a lower expected utility. On the contrary, a manager's utility increases in $c$ as both $k_{s}^{*}$ and $k_{p}^{*}$ increase in $c$. This can be explained as follows. Recall from our discussion following Proposition 2 that both a higher $q$ and higher $v_{2}$ reduce the misalignment in incentives between the managers and the firm. As such, they make the manager more willing to exert high effort and also to disclose his signal truthfully. Conversely, a higher $c$ makes high effort more costly for the manager, and widens the incentive misalignment with the firm. A lower (higher) misalignment in incentives, in turn, results in lower (higher) information rents for the manager, and consequently, to higher (lower) profits for the firm.

\subsection{The Optimal Product Evaluation Strategy}

Given the optimal contract structure, and the corresponding information rents for each evaluation strategy, we can now derive the firm's optimal product evaluation strategy. In addition, in this section, we compare this optimal strategy with the option of outsourcing the product evaluation to an external provider. This comparison is important because outsourcing is often considered an effective way to mitigate the inefficiencies caused by the misalignment of incentives within the organization.

Proposition 4 (The Optimal Product Evaluation Strategy). Define $\zeta_{4} \equiv \frac{\zeta_{1}}{2} \cdot \frac{(2 q-1)\left(v_{2}-z_{2}\right)}{\left(q v_{2}+v_{1}+(1-q) z_{2}+z_{1}\right)+\frac{k_{p}^{*}}{k_{s}^{*}}\left(q v_{2}+v_{1}-(3+q) z_{2}+z_{1}\right)}$. The firm's optimal product evaluation strategy 
is to incentivize both managers to exert (i) high effort if $c \leq \zeta_{4}$; and (ii) low effort if $c>\zeta_{4}$. Moreover, $\zeta_{4}<\zeta_{1}$ and there exist parameter values such that $\zeta_{4}>\zeta_{2}$.

As we would intuitively expect, the presence of information asymmetry between the managers and the firm makes the process of product evaluation "more expensive" to the firm. As a result, the area for which product evaluation is undertaken shrinks. This is clearly illustrated in Figure 4 which plots the firm's optimal evaluation strategy vis-à-vis the first-best benchmark (dashed line): In the region ABFEC the firm does not undertake any high-effort product evaluation, even though it is optimal to do so in the first-best case. Mathematically, this corresponds to $\zeta_{4}<\max \left\{\zeta_{1}, \zeta_{3}\right\}$.

Interestingly, however, this result does not imply that the firm always undertakes less evaluation effort compared to the first-best benchmark. On the contrary, when $\zeta_{4}>\zeta_{2}$ (region CED in Figure 4), the firm undertakes more evaluation effort by exerting high-effort evaluation for both products whereas in the first-best policy the firm exerts high-effort evaluation for only one of them. In other words, the firm is actually over-investing in information acquisition compared to the first-best benchmark. This over-investment in information is caused by the fact that the firm cannot observe either the managers' efforts or the outcomes of their evaluation. In addition, as discussed in Lemma 2, the firm cannot offer a truth-telling contract that incentivizes a high-effort evaluation for one product and a low-effort evaluation for the other one. Consequently, either manager can claim that he exerted high-effort evaluation, and therefore, request resources for his project.

Figure 4: The firm's optimal product evaluation strategy.

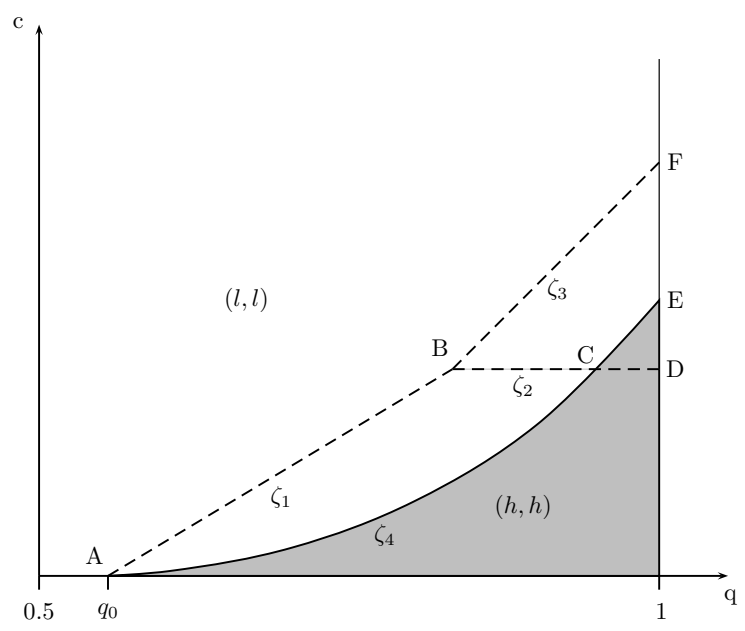

The firm's optimal contract induces (i) $e^{*}=(h, h)$ in the light gray region; and (ii) $e^{*}=(l, l)$ in the white area.

\section{Outsourcing as a Product Evaluation Strategy}

A key managerial implication from the previous discussion is that information asymmetries can significantly distort the firm's product evaluation strategy. Some firms attempt to circumvent 
Figure 5: Information asymmetry and outsourcing.

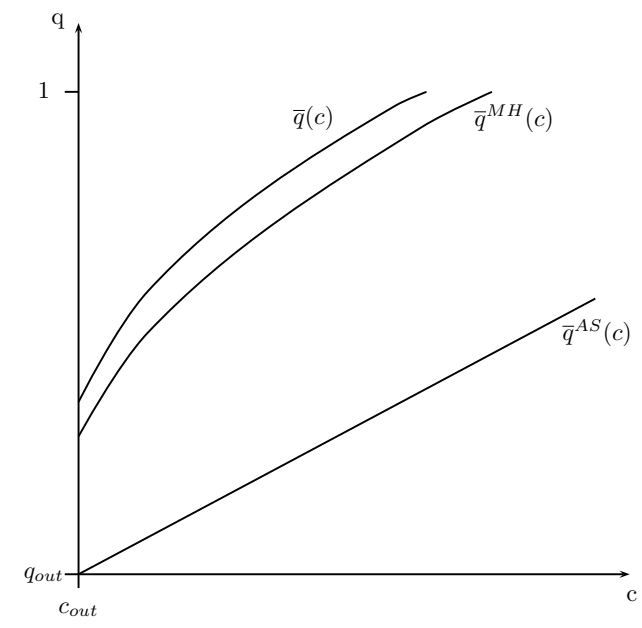

For any information structure, the firm prefers outsourcing below the respective threshold function.

this distortion by outsourcing their evaluation processes to external providers. The main premise of this remedy is that external providers can offer more objective evaluations as they are not subject to the various organizational dynamics, such as the managerial competition for resources. At the same time, however, it is reasonable to expect that the firm's managers know more about their products, and as such, their evaluations are more accurate. As such, the firm needs to consider whether the benefits of circumventing the effects of information asymmetry outweigh the negative implications of a lower information precision.

Let $q_{\text {out }}<q$ and $c_{\text {out }}$ denote the information precision and cost, respectively, when the evaluation process is outsourced. Proposition 5 characterizes the optimal product evaluation strategy by comparing the firm's profits under the optimal internal product evaluation strategy (Proposition 4) with the firm's profits under an outsourced product evaluation strategy. For expositional clarity, in Figure 5 we plot the more typical case where outsourcing offers a cost advantage compared to in-house evaluation (due to economies of scale or specialization), i.e., $c_{\text {out }}<c$, but the results of Proposition 5 hold for any values of $c$.

Proposition 5 (Outsourcing). (i) There exists a unique $\bar{q}(c)$ such that, it is optimal for the firm to keep the product evaluation in-house, if and only if $q \geq \bar{q}(c)$.

(ii) Let $\bar{q}^{M H}(c), \bar{q}^{A S}(c)$, and $\bar{q}^{F B}(c)$ denote the corresponding threshold values under pure moral hazard, pure adverse selection, and under first-best. Then, $\bar{q}(c) \geq \bar{q}^{M H}(c)>\bar{q}^{A S}(c)=$ $\bar{q}^{F B}(c)$. Moreover, $\bar{q}(c)-\bar{q}^{A S}(c)$ and $\bar{q}^{M H}(c)-\bar{q}^{A S}(c)$ increase concavely in $c$.

(iii) Lastly, $\bar{q}(c)$ and $\bar{q}^{M H}(c)$ increase concavely in $c$, while $\bar{q}^{A S}(c)$ increases linearly in $c$.

The first part of Proposition 5 states that a firm is better off keeping the evaluation process in-house, and therefore, incurring the implications of information asymmetries, as long as its managers can provide information of sufficiently higher precision $(q>\bar{q}(c))$. Clearly, as in-house evaluation becomes more expensive, an even higher precision is required to offset the increasing 
cost advantage of outsourcing, i.e., $\bar{q}(c)$ increases in $c$. In the pharmaceutical industry, the typical example of an outsourced evaluation process are the Phase III clinical trials. Those trials are outsourced to Contract Research Organizations (CRO) such as Parexel or Quintiles, that specialize in these processes and perform clinical trials for multiple pharmaceutical companies. Importantly, this is a regulated stage, with clear signals about the performance of the drug, and as such, performing them in-house doesn't offer any significant benefit. On the other hand, what constitutes a successful outcome during Phase IIa clinical trials may largely depend on a firm's business strategy and risk perception, and as such, firm-specific capabilities and knowledge can play a key role in the selection process. Our analysis would suggest that firms are more likely to outsource a Phase III clinical trial than a Phase IIa clinical trial.

The second part of Proposition 5 examines how the critical threshold $\bar{q}(c)$ changes under different information structures. First note that, consistent with our earlier discussion (before Lemma 3), when effort is contractible and information asymmetry stems only from adverse selection, the firm can achieve first-best profits. That is why $\bar{q}^{A S}(c)=\bar{q}^{F B}(c)$. In this case, the comparison between an in-house versus an outsourced product evaluation is entirely driven by the additional value of a higher precision versus the relatively higher cost, rather than the indirect costs of information asymmetry. However, under pure moral hazard, a significantly higher internal information precision is required, i.e., $\bar{q}^{M H}(c)>\bar{q}^{A S}(c)$. Interestingly, combining moral hazard and adverse selection, only moderately increases the threshold, $\bar{q}(c)$. This result implies that, all else being equal, firms are more likely to outsource the product evaluation when they cannot observe the efforts of their managers. This happens because a large portion of a manager's information rents are attributed to the non-verifiability of effort (Lemma 3). On the other hand, if efforts are verifiable, not being able to observe and interpret the signals generated by the product evaluation process, should not affect the firm's propensity to outsource. In addition, the fact that the difference between the thresholds increases in $c$ highlights that the distortion caused by the information asymmetry increases in the evaluation cost, $c$.

Lastly, the fact that $\bar{q}(c)$ and $\bar{q}^{M H}(c)$ increase concavely in $c$ (Proposition 5(iii)) reveals a rather counter-intuitive insight regarding the relationship between the evaluation precision, $q$, and the cost of information acquisition, $c$. One would expect that as information becomes more expensive ( $c$ increases), the marginal value of more precise information $(\partial \Pi / \partial q)$ would decrease. Yet, as we show in the Appendix (proof of Proposition 5), the concavity of $\bar{q}(c)$ is driven by the positive cross-partial derivative of the firm's profits with respect to $q$ and $c$ (i.e., $\partial^{2} \Pi / \partial q \partial c>0$ ). This complementarity between $q$ and $c$ leads to an important insight: a higher precision, $q$, is relatively more important for the firm when the information acquisition costs are high. This happens because when information is more reliable, the firm can not only allocate its resources better, but it can also incentivize the managers to exert effort at a lower cost. In short, a higher $q$ reduces the misalignment of incentives between the firm and the managers. This is particularly important when the managers face high private costs, that is, when $c$ is high. An alternative explanation is also instructive: firm profits decrease in $c$ as the firm needs to pay higher bonuses, but when $q$ is high, this profit reduction is mitigated by the 
more efficient resource allocation. In short, more efficient resource allocation processes (through better information) are critical when effort is expensive.

\section{The Effect of Information Asymmetry on the Firm's Product Portfolio Scope and Profitability}

So far, we have discussed the effects of information asymmetry on the firm's optimal product evaluation strategy. This evaluation strategy, in turn, determines the information that the firm has available when making its resource allocation decisions, and therefore, the firm's product portfolio scope. While the extant literature in NPD has studied extensively the information acquisition process for a single project (e.g., Thomke, 2007, and references therein) and the resource allocation decisions for the product portfolio (e.g., Kavadias and Chao 2007, and references therein), the effect of the former on the latter has been rather overlooked. In particular, the extant literature provides little insights on whether the presence of asymmetric information, at the product evaluation stage, would lead to an overly broad or narrow portfolio scope compared to the first-best benchmark. In this section, we begin by investigating how changes in the firm's evaluation strategy affect its product portfolio scope. We then examine the firm's profits and the social welfare, and identify the conditions where information asymmetry leads to greater or lesser profit and welfare losses.

\subsection{Product Portfolio Scope}

Before discussing the effect of information asymmetry on the firm's product portfolio scope, it is instructive to clarify the relationship between the product evaluation strategy and the product portfolio scope for the first-best policy. From Lemma 1 and Proposition 1, we have the following direct observations: (i) when the firm pursues low-effort evaluation for both products, it always ends up splitting resources evenly across products, and thus, developing both products; (ii) when the firm pursues high-effort evaluation for only one of the products, and the information is relatively reliable, then the firm always develops a single product; (iii) when the firm pursues high-effort evaluation for both of its products, then it is equally likely that the firm develops one or two products.

In other words, there is a non-monotonic relationship between the extent of product evaluation and the number of products that the firm develops: a firm with little information spreads its risks across both products to increase the chance that at least one product is successful, a partially informed firm makes a crude decision by developing only one, while a fully informed firm might choose either allocation strategy depending on its refined information. This non-monotonic effect is illustrated in Figure 6 which plots the first-best expected product development scope, $n^{F B}$, for all possible cases (dashed line). Proposition 6 sheds light on how information asymmetry affects the firm's product portfolio scope, $n$. 
Proposition 6 (Product Portfolio Scope). For any given $q$ and $c$, information asymmetry weakly increases a firm's expected product portfolio scope, i.e., $n \geq n^{F B}$.

Proposition 6 highlights that information asymmetries lead a firm to broaden its product portfolio scope compared to the first-best benchmark. Recall from Proposition 4 that in some regions, managerial competition results in under-investment in information (region ABFEC in Figure 4), while in others it results in over-investment (region CED in Figure 4). In either case, the information asymmetry between the firm and its managers impedes an asymmetric product evaluation strategy, which corresponds to launching a single product on the market. Instead, the firm has to choose between spreading its bets across products under limited information versus a more refined, but overly costly product portfolio allocation.

Figure 6: Expected scope of product development.
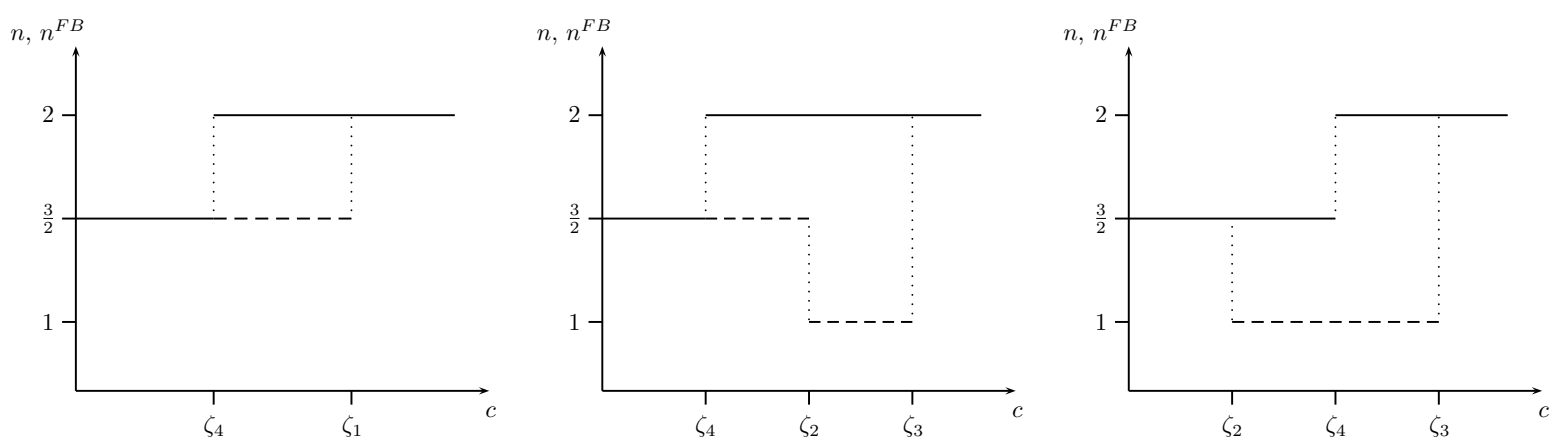

The firm's expected product development scope under information asymmetry (solid line) and first-best conditions (dashed line) for $q<q_{c}$ (left), $q \geq q_{c}$ and $\zeta_{4}<\zeta_{2}$ (middle), and $q \geq q_{c}$ and $\zeta_{4} \geq \zeta_{2}$ (right), respectively.

\subsection{Profit and Welfare Loss}

To measure the efficiency of the firm's contract scheme, we employ two different performance indicators: the firm's percentage profit loss, which captures the effect of the product evaluation process on the firm's profits, $\eta_{p} \equiv 1-\frac{\Pi\left(e^{*}\right)}{\Pi^{F B}\left(e^{F B}\right)}$, and the percentage welfare loss, which reflects the loss in total welfare due to misaligned incentives, $\eta_{w} \equiv 1-\frac{\Pi\left(e^{*}\right)+U_{i}\left(e^{*}\right)+U_{j}\left(e^{*}\right)}{\Pi^{F B}\left(e^{F B}\right)}$. These two performance measures quantify the implications of information asymmetry on two different levels of aggregation. While $\eta_{p}$ captures the effect on the firm's level, $\eta_{w}$ measures the contract's social efficiency for the entire system (firm and managers).

Proposition 7 (Profit Loss and Social Inefficiency). If the firm under-(over-)invests in product evaluation, then $\eta_{p}>0$ and $\eta_{w}>0$ increase (decrease) in $q$ and $v_{2}$, and decrease (increase) in c. If $e^{*}=e^{F B}=(h, h)$, then $\eta_{w}=0$, and $\eta_{p}>0$ decreases in $q$ and $v_{2}$, and increases in c. Otherwise, if $e^{*}=e^{F B}=(l, l)$, then $\eta_{p}=\eta_{w}=0$.

According to Proposition 7, the effect of information asymmetry varies significantly across the different regions depicted in Figure 4. Recall from Figure 4 that if the cost of information acquisition is very high $\left(c>\max \left\{\zeta_{1}, \zeta_{3}\right\}\right)$, then the firm never exerts any high-effort product 
evaluation, and therefore, the firm does not need to incentivize its managers. As such, the firm is able to accrue all the profits $\left(\eta_{p}=0\right)$, and the employed compensation scheme is socially efficient $\left(\eta_{w}=0\right)$. This finding is part of a very general result of Proposition 7. If information asymmetries do not affect the firm's optimal product evaluation strategy, then there is no welfare loss; the total generated value remains intact $\left(\eta_{w}=0\right)$ and it is only the distribution of profits between the firm and the managers that changes $\left(\eta_{p} \geq 0\right)$. As discussed in Figure 4, this happens either when the information precision is very high and the evaluation cost very low, or at the other extreme, when the information precision is very low and the evaluation cost very high. In the former case, information acquisition is so effective that the firm always evaluates both products, while in the latter, it is so ineffective that the firm always chooses to forgo costly product evaluation. In reality, however, most firms face environments where valuable information is also costly. Importantly, in these regions, information asymmetry interferes with the firm's optimal evaluation strategy, and leads to welfare and profit losses.

When the firm under-invests in product evaluation (region ABFEC in Figure 4), i.e., collects less information than is socially optimal, then $\eta_{p}$ and $\eta_{w}$ increase in $q$ and $v_{2}$, and decrease in $c$. Intuitively, as the firm under-invests in product evaluation, a higher $q$ implies that more valuable information is lost, and therefore the profit and welfare loss becomes steeper. Obviously, this effect is even more severe as $v_{2}$ increases, and the value of ex-post winner-picking is higher.

Lastly, when the firm induces high-effort product evaluation (region under ACE) for both products, $\eta_{p}$ decreases in $q$ and $v_{2}$, and increases in $c$. As discussed in Proposition 3 , in that region a higher $q$ or $v_{2}$ reduces the incentive misalignment between the managers and the firm, while a higher $c$ widens it. The former effect reduces the firm's profit losses, whereas the latter increases it. Similarly, if the firm gathers more information than under the first-best policy, i.e., the firm over-invests in product evaluation (region CED), then the social value of this additional information gain increases as the information precision becomes higher and the evaluation costs lower.

\section{Conclusions}

This paper aims at understanding a key concern of many senior $\mathrm{R} \& \mathrm{D}$ executives: "how do you make good decisions when the information you need to make those decisions comes largely from the project champions who are competing against one another for resources" (Sharpe and Keelin, 1998, p. 45). Prior academic literature has extensively discussed the importance of such a question when managing parallel projects (e.g., Loch et al., 2006), but without offering explicit guidance on how to structure appropriate incentive mechanisms that address these challenges. This is also highlighted in Lerner (2012, p. 170) who emphasizes that "one crucial, though often neglected, point is that such tolerance for failure requires a rethinking not just of compensation schemes, but also of how projects are selected and funded. [...] A question that would reward both further research by economic theorists and real-world exploration is how to induce 'truthtelling' when evaluating high-risk innovative projects". The main goal of this paper is to offer 
a formal framework on the tradeoffs involved between incentivizing information acquisition and truthful revelation among new product development teams. More specifically, our study makes the following contributions in the extant literature and suggests a set of corresponding hypotheses for empirical validation.

First, we show that products characterized by different levels of precision in their evaluation processes, require incentives of fundamentally different structure. For example, in the pharmaceutical industry new compounds are classified either as "new molecular entities" (NME) or as "me-too" drugs. In the former case, due to the highly novel structure of the compound, the results of even the most rigorous evaluation methods are "extremely sensitive", and cannot provide accurate information regarding the potential of the drug. On the contrary, in the latter case, because "the mechanisms of action" are well-understood, a thorough evaluation process can lead to highly precise estimations. The key managerial implication from our analysis, is that those two different types of drugs, require completely different types of incentives: "metoo" drugs require an emphasis on individual incentives whereas NMEs require an emphasis on shared incentives. Thus, companies with a "one size fits all" approach in their incentive schemes (similar to the ones we discussed in our motivating examples), will invariably over-emphasize one aspect of the evaluation process at the expense of the other.

Hypothesis 1. Products for which the evaluation process is less (more) predictive of their success are associated with a stronger emphasis on shared (individual) rather than individual (shared) incentives.

Second, our model illustrates how the incentive misalignment within an organization can severely hinder its product evaluation processes. To circumvent these inefficiencies, companies often decide to outsource their evaluation processes to external providers, e.g., in the pharmaceutical industry such companies are called Contract Research Organizations (CRO). Intuitively, an outsourcing strategy is optimal when a product's evaluation does not require knowledge that can only be found in-house, that is, when the expertise of an external provider is comparable to the internal expertise. An example of such evaluation processes are Phase III clinical trials that aim to prove that the efficacy of a drug is "statistically significant". These evaluation processes are rather standardized, with clear criteria and regulated performance thresholds. On the contrary, during Phase II trials, what comprises sufficiently good or bad evidence for the progression of a compound may depend on company-specific expertise and characteristics. Moreover, we show that the presence of asymmetric information may significantly lower the threshold regarding the minimum precision of an external provider, particularly so, when the cost of information acquisition is high. In those regions, senior management should aim to reduce the extent of asymmetric information (by perhaps facilitating better communication and coordination mechanisms), and therefore, make the in-house evaluation the optimal strategy rather than relying on outsourcing.

Hypothesis 2. A firm is more likely to outsource its product evaluation when the external provider's level of expertise is closer to its own. 
Hypothesis 3. A firm is more likely to outsource the evaluation process for products for which the internal evaluation process cannot be monitored.

Lastly, our analysis highlights the role of asymmetric information on the firm's product portfolio scope. In particular, we find that, compared to the first-best benchmark, too many products are funded, leading to many failures and inefficient use of the firm's resources. These high attrition rates and the corresponding low $\mathrm{R} \& \mathrm{D}$ productivity is a major concern for almost all pharmaceutical companies. Recent research has empirically shown that more decentralized firms tend to manufacture too many products, attributing the effect to the managers' local preferences which are not necessarily aligned with the firm's strategy (Thomas, 2011). Our paper offers an alternative explanation for such overly broad product portfolios: the presence of asymmetric information during the product evaluation stage. The key managerial implication from this result is that any effort to reduce the extent of this information asymmetry, and particularly the moral hazard component, can play a key role in improving the firm's product portfolio. Several firms in the pharmaceutical industry have attempted to make the product evaluation process more transparent by removing the barriers of the functional silos and replace them with highly integrated centers that focus on specific therapeutic areas. According to a recent study of eight big pharmaceutical companies, those companies outperformed competitors across several performance metrics of R\&D productivity due to the "strong interfaces between the research and the development unit" (Held et al., 2009, p. 106).

Hypothesis 4. Firms with evaluation processes characterized by high levels of asymmetric information are more likely to have an overly broad product portfolio scope.

In order to maintain tractability and develop a parsimonious model, we have made some assumptions regarding the role of product managers, and correspondingly, the specific functional forms of the incentive structure. Specifically, our paper focuses on the project selection stage of $\mathrm{NPD}$, and as such, on the evaluation rather than the generation of different alternatives (e.g., higher effort in our setting improves the selection process but not the quality of the different alternatives). Recent work has offered important insights on the structure of the opportunity spaces (Kornish and Ulrich, 2011) as well as on the effect of asymmetric information on the search process itself (Mihm et al., 2010). Moreover, our analysis considers ex-ante symmetric projects. In practice, firms are often faced with projects that vary significantly with respect to their state of execution, uncertainty, and need for resources. While our model captures some first-order effects regarding the interplay between information acquisition and resource allocation, we believe that capturing tradeoffs among projects that evolve over time is a fruitful avenue for future research.

\section{Acknowledgments}

The authors are grateful to Don Drakeman, Venture Partner at life-sciences venture capital firm Advent Venture Partners and Fellow in Health Management at Judge Business School, for 
insightful and transformative discussions about the pharmaceutical industry. The authors are also grateful for the constructive suggestions made by Stylianos Kavadias, Jeremy HutchisonKrupat, three anonymous reviewers, the associate editor, and the department editor.

\section{Appendix. Proofs}

Proof of Lemma 1. The firm's optimal resource allocation for each realization of $e$ and $m$ maximizes the expected market value of both products, $\mathbb{E}_{\theta}\left[\nu_{i}+\nu_{j} \mid m, e\right]$, with the expectation taken over the products' market potential. The proof now proceeds by comparing the expected market value, $\mathbb{E}_{\theta}\left[\nu_{i}+\nu_{j} \mid m, e\right]=\sum_{i} \operatorname{Pr}\left(\theta_{i}=G \mid m_{i}, e_{i}\right) \nu_{i}\left(\theta_{i}=G\right)+\operatorname{Pr}\left(\theta_{i}=B \mid m_{i}, e_{i}\right) \nu_{i}\left(\theta_{i}=B\right)$, of different resource allocation schemes for all $e$ and $m$, given that managers truthfully reveal their signals, $m=s$.

Suppose $e=(l, l)$. Then, $\operatorname{Pr}\left(\theta_{i}=G \mid m_{i}, e_{i}=l\right)=1 / 2$ for any $m$. If the firm invests all its resources in a single product, then $\mathbb{E}_{\theta}\left[\nu_{i}+\nu_{j} \mid m, e\right]=\left(v_{2}+z_{2}\right) / 2$. If, in contrast, the firm splits resources evenly, then $\mathbb{E}_{\theta}\left[\nu_{i} \mid m, e\right]=\left(v_{1}+z_{1}\right) / 2$, yielding $\mathbb{E}_{\theta}\left[\nu_{i}+\nu_{j} \mid m, e\right]=v_{1}+z_{1}$. Since by assumption $v_{2}<2 v_{1}$ and $z_{2}<2 z_{1}$, the firm's optimal resource allocation for $e=(l, l)$ and any $m$ is to split resources evenly.

Now, suppose $e=(h, h)$. In this setting, $\operatorname{Pr}\left(\theta_{i}=G \mid m_{i}=g, e_{i}=h\right)=q$ and $\operatorname{Pr}\left(\theta_{i}=\right.$ $\left.G \mid m_{i}=b, e_{i}=h\right)=1-q$. Assume $m_{i}=m_{j}$, implying that posterior beliefs for both products are also identical. As such, the firm maximizes the expected market value of both products by splitting resources evenly. Now, assume $m=(g, b)$. Allocating all resources to product $i$ gives $\mathbb{E}_{\theta}\left[\nu_{i}+\nu_{j} \mid m, e\right]=q v_{2}+(1-q) z_{2}$, while after an even split of resources $\mathbb{E}_{\theta}\left[\nu_{i}+\nu_{j} \mid m, e\right]=$ $q\left(v_{1}+z_{1}\right)+(1-q)\left(v_{1}+z_{1}\right)=v_{1}+z_{1}$. It follows that the firm optimally allocates all resources to product $i$ if $q>\left(v_{1}+z_{1}-z_{2}\right) /\left(v_{2}-z_{2}\right)=q_{0}$, and splits resources evenly otherwise.

Lastly, suppose $e=(h, l)$. As the recommendation for product $j$ is uninformative, the firm allocates resources only based on the recommendation for product $i$. If the firm receives a good recommendation for product $i$, then allocating all resources to product $i$ yields $\mathbb{E}_{\theta}\left[\nu_{i}+\nu_{j} \mid m, e\right]=$ $q v_{2}+(1-q) z_{2}$. Splitting resources evenly, however, results in $\mathbb{E}_{\theta}\left[\nu_{i}+\nu_{j} \mid m, e\right]=q v_{1}+v_{1} / 2+(1-$ $q) z_{1}+z_{1} / 2$. Thus, it is optimal for the firm to split resources evenly only if $q<q_{g}$, and allocate all resources to product $i$ otherwise. Now, suppose the recommendation for product $i$ is bad. Then, it is never optimal to allocate both resources to product $i$. An even split of resources yields $\mathbb{E}_{\theta}\left[\nu_{i}+\nu_{j} \mid m, e\right]=(1-q) v_{1}+v_{1} / 2+q z_{1}+z_{1} / 2$, whereas $\mathbb{E}_{\theta}\left[\nu_{i}+\nu_{j} \mid m, e\right]=\left(v_{2}+z_{2}\right) / 2$ if all resources are allocated to product $j$. Hence, the firm optimally splits resources evenly only if $q<q_{b}$, and allocates all resources to product $j$ otherwise.

Proof of Proposition 1. We prove this proposition in three steps: First, we derive the firm's first-best expected profit for any possible product evaluation strategy. Second, we establish that the firm never chooses an asymmetric evaluation strategy if $q<q_{g}$. Lastly, we discuss the threshold functions $\zeta_{1}, \zeta_{2}$, and $\zeta_{3}$.

Profit derivation: If $e=(l, l)$, the firm eventually splits its resources evenly across the two products. Therefore, product $i$ 's ex-ante expected market value is $\mathbb{E}_{\theta}\left[\nu_{i} \mid e=(l, l)\right]=\sum_{s_{i}} \operatorname{Pr}\left(\theta_{i}=\right.$ 
$\left.G \mid s_{i}\right) \operatorname{Pr}\left(s_{i}\right) v_{1}+\operatorname{Pr}\left(\theta_{i}=B \mid s_{i}\right) \operatorname{Pr}\left(s_{i}\right) z_{1}=\frac{v_{1}+z_{1}}{2}$. Due to the symmetry of products and since no evaluation costs are incurred, the firm's ex-ante expected profit becomes

$$
\Pi^{F B}(e=(l, l))=v_{1}+z_{1} .
$$

In contrast, for $e=(h, h)$, the firm incurs evaluation costs for both products, but also revises its initial beliefs about the true market potential of the two products. If $q \leq q_{0}$, then the firm always splits resources evenly, and following (1), expected profits are $v_{1}+z_{1}-2 c$, which can never be optimal. In contrast, if $q>q_{0}$, the firm may either split resources evenly if products are equally promising, or it may fund only one of the products. Therefore, $\mathbb{E}_{\theta}\left[\nu_{i} \mid e=(h, h)\right]=$ $\frac{1}{4}\left(q v_{2}+v_{1}+(1-q) z_{2}+z_{1}\right)$, and consequently,

$$
\Pi^{F B}(e=(h, h))=\frac{1}{2}\left(q v_{2}+v_{1}+(1-q) z_{2}+z_{1}\right)-2 c .
$$

Lastly, for $e=(h, l)$, the derivation of the firm's ex-ante expected profit is similar to the above cases. However, we need to consider that the optimal resource allocation changes with $q$ (see Lemma 1). Thus,

$$
\Pi^{F B}(e=(h, l))= \begin{cases}v_{1}+z_{1}-c & \text { if } q<q_{b} \\ \frac{1}{4}\left(v_{2}+(2 q+1) v_{1}+z_{2}+(3-2 q) z_{1}\right)-c & \text { if } q_{b} \leq q<q_{g} \\ \frac{1}{4}\left((2 q+1) v_{2}+(3-2 q) z_{2}\right)-c & \text { if } q \geq q_{g} .\end{cases}
$$

Asymmetric evaluation: We now show that, in optimum, the firm never chooses $e=(h, l)$ if $q<q_{g}$. First, for $q<q_{b}, \Pi^{F B}(e=(h, l))=v_{1}+z_{1}-c<v_{1}+z_{1}=\Pi^{F B}(e=(l, l))$ because $c>0$ by assumption. Second, $e=(h, l)$ is also dominated for $q_{b} \leq q<q_{g}$, i.e., $\Pi^{F B}(e=(h, l))>$ $\max \left\{\Pi^{F B}(e=(l, l)), \Pi^{F B}(e=(h, h))\right\}$ is a contradiction. In fact, $\Pi^{F B}(e=(h, l))>\Pi^{F B}(e=$ $(h, h))$ if and only if $c>(2 q-1)\left[v_{2}-v_{1}-z_{2}+z_{1}\right] / 4 \equiv \underline{c}$; and $\Pi^{F B}(e=(h, l))>\Pi^{F B}(e=(l, l))$ if and only if $c<\left[v_{2}+(2 q-3) v_{1}+z_{2}-(2 q+1) z_{1}\right] / 4 \equiv \bar{c}$. However, $\bar{c}<\underline{c}$, which yields the desired contradiction.

Optimal product evaluation: The threshold functions $\zeta_{1}, \zeta_{2}$, and $\zeta_{3}$ are derived by pairwise comparing (1) with (2), (2) with (3), and (1) with (3), respectively. Accordingly, the firm chooses $e=(h, h)$ if $c \leq \min \left\{\zeta_{1}, \zeta_{2}\right\}, e=(h, l)$ if $\zeta_{2}<c \leq \zeta_{3}$, and $e=(l, l)$ if $c>\max \left\{\zeta_{1}, \zeta_{3}\right\}$. By noting that $q_{c} \geq q_{g}$ if and only if $q_{c} \leq 1$, we conclude: (i) If $q<q_{c}$, then $\zeta_{3}<\zeta_{1}<\zeta_{2}$. Thus, $e^{F B}=(h, h)$ for $c \leq \zeta_{1}$, and $e^{F B}=(l, l)$ otherwise. (ii) If $q \geq q_{c}$, then $\zeta_{2}<\zeta_{1}<\zeta_{3}$. Thus, $e^{F B}=(h, h)$ for $c \leq \zeta_{2}, e^{F B}=(h, l)$ for $\zeta_{2}<c \leq \zeta_{3}$, and $e^{F B}=(l, l)$ otherwise.

Proof of Lemma 2. The proof proceeds in two steps. First, we revisit the firm's optimal resource allocation. Second, we show that a compensation scheme that induces asymmetric effort levels is never incentive compatible in effort.

Resource allocation: If both managers are truth-telling, but pursue different evaluation effort levels, then the firm is not able to observe the managers' product evaluation strategy. In 
fact, the firm does not know whether $e=(h, l)$ or $e=(l, h)$. This ambiguity has to be taken into account when allocating resources to products (Lemma 1 is not straightforward applicable because $e$ is not known).

Suppose $m_{i}=m_{j}$. If recommendations are good, then $\mathbb{E}_{\theta}\left[\nu_{i}+\nu_{j} \mid m, e\right]=q v_{1}+(1-q) z_{1}+$ $\left(v_{1}+z_{1}\right) / 2$ if the firm splits resources evenly, while allocating all resources to one product gives $\mathbb{E}_{\theta}\left[\nu_{i}+\nu_{j} \mid m, e\right]=\left(q v_{2}+(1-q) z_{2}+\left(v_{2}+z_{2}\right) / 2\right) / 2$. Similarly, if both recommendations are bad, then an even split of resources yields $\mathbb{E}_{\theta}\left[\nu_{i}+\nu_{j} \mid m, e\right]=(1-q) v_{1}+q z_{1}+\left(v_{1}+z_{1}\right) / 2$, while allocating all resources to one product gives $\mathbb{E}_{\theta}\left[\nu_{i}+\nu_{j} \mid m, e\right]=\left((1-q) v_{2}+q z_{2}+\left(v_{2}+z_{2}\right) / 2\right) / 2$. Thus, it is optimal to split resources evenly across products if recommendations are identical.

Now, assume $m=(g, b)$. Allocating all resources to product $i$ gives $\mathbb{E}_{\theta}\left[\nu_{i}+\nu_{j} \mid m, e\right]=$ $\left(q v_{2}+(1-q) z_{2}+\left(v_{2}+z_{2} / 2\right) / 2\right.$, whereas splitting resources evenly yields $\mathbb{E}_{\theta}\left[\nu_{i}+\nu_{j} \mid m, e\right]=v_{1}+z_{1}$. Therefore, the firm invests all resources in product $i$ if $q \geq\left(4 v_{1}-v_{2}+4 z_{1}-3 z_{2}\right) / 2\left(v_{2}-z_{2}\right)$, and splits resources evenly otherwise.

Incentive compatibility: By using the firm's optimal resource allocation, we conclude this proof by showing that any truth-telling contract with $e_{i} \neq e_{j}$ is never incentive compatible in effort, i.e., one manager always wants to deviate from his current effort level, such that $e_{i} \neq e_{j}$ cannot be part of any equilibrium.

If $q<\left(4 v_{1}-v_{2}+4 z_{1}-3 z_{2}\right) / 2\left(v_{2}-z_{2}\right)$, then the firm always allocates resources equally to both products. Hence, exerting high-effort product evaluation is costly for a manager, but does not affect the firm's allocation decision. Therefore, each manager's expected utility is always largest under low-effort product evaluation.

If $q \geq\left(4 v_{1}-v_{2}+4 z_{1}-3 z_{2}\right) / 2\left(v_{2}-z_{2}\right)$, then the firm allocates all resources to a single product if recommendations are unequal, and splits resources evenly elsewise. Without loss of generality, assume $e=(h, l)$, and suppose that a truth-telling contract exists. Then, this contract must be incentive compatible in effort, i.e., $U_{i}\left(e_{i}=h \mid e_{j}=l, m=s\right) \geq U_{i}\left(e_{i}=l \mid e_{j}=l, m=s\right)$, and $U_{j}\left(e_{j}=h \mid e_{i}=h, m=s\right)<U_{j}\left(e_{j}=l \mid e_{i}=h, m=s\right)$. Manager $i$ 's effort incentive compatibility condition is satisfied if $2 k_{s}\left(q v_{2}+(1-q) z_{2}\right)-8 c \geq k_{s}\left(v_{2}+z_{2}\right)$, while manager $j$ 's constraint is true if $2 k_{s}\left(q v_{2}+(1-q) z_{2}\right)-8 c<k_{s}\left(v_{2}+z_{2}\right)$. Since the two constraints contradict each other, we conclude that there exists no symmetric contract that induces asymmetric effort levels.

Proof of Lemma 3. This proof consists of two steps. As a first step, we derive the firm's optimization problem $(\mathrm{P})$ - (LL). Step two determines the optimal wage contract that induces high-effort product evaluation under public signals.

Optimization problem: The firm's expected profit $(\mathrm{P})$ is similar to (2). However, the firm does not directly incur the effort $\operatorname{costs} c$, but it has to incentivize its managers to exert high effort by paying a bonus scheme $k=\left(k_{0}, k_{s}, k_{p}\right)$. Thus, the firm maximizes its expected profits, $\Pi(k)=\left(1-k_{s}-k_{p}\right) \mathbb{E}_{\theta}\left[\nu_{i}+\nu_{j} \mid k\right]-2 k_{0}=\left(1-k_{s}-k_{p}\right) \frac{1}{2}\left(q v_{2}+v_{1}+(1-q) z_{2}+z_{1}\right)-2 k_{0}$. We now turn to the truth-telling constraints (IC-g) and (IC-b). Manager $i$ truthfully reveals a good signal if and only if $U_{i}\left(m_{i}=g \mid s_{i}=g, e_{i}=e_{j}=h, m_{j}=s_{j}\right) \geq U_{i}\left(m_{i}=b \mid s_{i}=g, e_{i}=e_{j}=h, m_{j}=s_{j}\right)$, where the manager assumes that the firm will optimally allocate resources according to the managers' recommendations. Similarly, truthful revelation of a bad evaluation outcome is guaranteed if 
and only if $U_{i}\left(m_{i}=b \mid s_{i}=b, e_{i}=e_{j}=h, m_{j}=s_{j}\right) \geq U_{i}\left(m_{i}=g \mid s_{i}=b, e_{i}=e_{j}=h, m_{j}=s_{j}\right)$. The required utilities are derived as follows: $U_{i}\left(m_{i}=g \mid s_{i}=g, e_{i}=e_{j}=h, m_{j}=s_{j}\right)=$ $\mathbb{P}\left(s_{j}=g\right)\left(k_{0}+k_{s} \mathbb{E}_{\theta_{i}}\left[\nu_{i} \mid k, m, e\right]+k_{p} \mathbb{E}_{\theta_{j}}\left[\nu_{j} \mid k, m, e\right]\right)+\mathbb{P}\left(s_{j}=b\right)\left(k_{0}+k_{s} \mathbb{E}_{\theta_{i}}\left[\nu_{i} \mid k, m, e\right]\right)=\frac{1}{2}\left(k_{s}+\right.$ $\left.k_{p}\right)\left(q v_{1}+(1-q) z_{1}\right)+\frac{1}{2} k_{s}\left(q v_{2}+(1-q) z_{2}\right)+k_{0}$. Similarly, $U_{i}\left(m_{i}=b \mid s_{i}=g, e_{i}=e_{j}=h, m_{j}=s_{j}\right)=$ $\frac{1}{2} k_{p}\left(q v_{2}+(1-q) z_{2}\right)+\frac{1}{2}\left(k_{s}\left(q v_{1}+(1-q) z_{1}\right)+k_{p}\left((1-q) v_{1}+q z_{1}\right)\right)+k_{0}, U_{i}\left(m_{i}=g \mid s_{i}=b, e_{i}=\right.$ $\left.e_{j}=h, m_{j}=s_{j}\right)=\frac{1}{2}\left(k_{s}\left((1-q) v_{1}+q z_{1}\right)+k_{p}\left(q v_{1}+(1-q) z_{1}\right)\right)+\frac{1}{2} k_{s}\left((1-q) v_{2}+q z_{2}\right)+k_{0}$, and $U_{i}\left(m_{i}=b \mid s_{i}=b, e_{i}=e_{j}=h, m_{j}=s_{j}\right)=\frac{1}{2} k_{p}\left(q v_{2}+(1-q) z_{2}\right)+\frac{1}{2}\left(k_{s}+k_{p}\right)\left((1-q) v_{1}+q z_{1}\right)+k_{0}$. Canceling out identical terms gives the desired truth-telling conditions (IC-g) and (IC-b). In a next step, we analyze the firm's effort incentive condition (IC-e). Manager $i$ exerts higheffort product evaluation if and only if $U_{i}\left(e_{i}=h \mid e_{j}=h, m=s\right) \geq U_{i}\left(e_{i}=l \mid e_{j}=h, m=s\right)$, where the manager assumes that the firm will optimally allocate resources according to the managers' recommendations, and that recommendations are truthful. These utilities are given by: $U_{i}\left(e_{i}=h \mid e_{j}=h, m=s\right)=\mathbb{P}\left(s_{i}=g, s_{j}=g\right)\left(k_{0}+k_{s} \mathbb{E}_{\theta_{i}}\left[\nu_{i} \mid k, m, e\right]+k_{p} \mathbb{E}_{\theta_{j}}\left[\nu_{j} \mid k, m, e\right]\right)+$ $\mathbb{P}\left(s_{i}=g, s_{j}=b\right)\left(k_{0}+k_{s} \mathbb{E}_{\theta_{i}}\left[\nu_{i} \mid k, m, e\right]\right)+\mathbb{P}\left(s_{i}=b, s_{j}=g\right)\left(k_{0}+k_{p} \mathbb{E}_{\theta_{j}}\left[\nu_{j} \mid k, m, e\right]\right)+\mathbb{P}\left(s_{i}=\right.$ $\left.b, s_{j}=b\right)\left(k_{0}+k_{s} \mathbb{E}_{\theta_{i}}\left[\nu_{i} \mid k, m, e\right]+k_{p} \mathbb{E}_{\theta_{j}}\left[\nu_{j} \mid k, m, e\right]\right)-c=\frac{1}{4}\left(k_{s}+k_{p}\right)\left(q v_{1}+(1-q) z_{1}\right)+\frac{1}{4} k_{s}\left(q v_{2}+\right.$ $\left.(1-q) z_{2}\right)+\frac{1}{4} k_{p}\left(q v_{2}+(1-q) z_{2}\right)+\frac{1}{4}\left(k_{s}+k_{p}\right)\left((1-q) v_{1}+q z_{1}\right)+k_{0}-c$, and $U_{i}\left(e_{i}=l \mid e_{j}=\right.$ $h, m=s)=\frac{1}{4}\left(k_{s} \frac{1}{2}\left(v_{1}+z_{1}\right)+k_{p}\left(q v_{1}+(1-q) z_{1}\right)\right)+\frac{1}{4} k_{s} \frac{1}{2}\left(v_{2}+z_{2}\right)+\frac{1}{4} k_{p}\left(q v_{2}+(1-q) z_{2}\right)+$ $\frac{1}{4}\left(k_{s} \frac{1}{2}\left(v_{1}+z_{1}\right)+k_{p}\left((1-q) v_{1}+q z_{1}\right)\right)+k_{0}$. Collecting terms yields the firm's effort incentive constraint (IC-e). Lastly, the firm needs to ensure that wages are always non-negative, since managers are protected by limited liability. By $2 z_{1} \geq z_{2}$, a manager's minimum wage is either $k_{0}+k_{p} z_{2}$ or $k_{0}+k_{s} z_{2}$, which results in the limited liability constraints (LL).

Optimal contract: With public signals, the firm does not need to incentivize truth-telling by the managers. As a result, the firm can induce high-effort product evaluation by offering a contract that satisfies (IC-e), while adhering to the managers' limited liability constraints (LL). From (IC-e), it follows immediately that $k_{s} \geq \frac{8 c}{(2 q-1)\left(v_{2}-z_{2}\right)}$. It remains to optimally choose $k_{0}$ and $k_{p}$ such that (LL) is satisfied.

Firstly, suppose $k_{p} \leq k_{s}$. Then, (LL) implies $k_{0}=-k_{p} z_{2}$. For brevity, define $V \equiv$ $\frac{1}{2}\left(q v_{2}+v_{1}+(1-q) z_{2}+z_{1}\right)$. Inserting this into the firm's profit function $(\mathrm{P})$ gives $\Pi(k)=$ $\left(1-k_{s}-k_{p}\right) V+2 k_{p} z_{2}$. For $q \geq q_{d}$, we have $V-2 z_{2} \geq 0$. In this situation, $\Pi(k)$ decreases in $k_{s}$ and $k_{p}$, implying that the firm chooses $k_{s}$ and $k_{p}$ as low as possible, i.e., $k_{s}=\frac{8 c}{(2 q-1)\left(v_{2}-z_{2}\right)}$ and $k_{p}=0$. For $q<q_{d}$, we have $V-2 z_{2}<0$. In this situation, $\Pi(k)$ decreases in $k_{s}$, but increases in $k_{p}$. Thus, the firm chooses $k_{p}$ as high as possible. Given $k_{s} \geq k_{p}$, this implies $k_{p}=k_{s}$, i.e., both limited liability constraints (LL) are binding. Inserting $k_{p}=k_{s}$ into $\Pi(k)$ yields $\Pi(k)=V-2 k_{s}\left(V-z_{2}\right)$. Since $V-z_{2}>0, k_{s}$ is chosen as low as possible; i.e., by (IC-e), $k_{s}=\frac{8 c}{(2 q-1)\left(v_{2}-z_{2}\right)}$.

Lastly, suppose that in the optimal contract $k_{s}<k_{p}$. Then, the binding limited liability constraint is $k_{0}+k_{s} z_{2} \geq 0$, implying $k_{0}=-k_{s} z_{2}$ in optimum. In this case, $\Pi(k)$ decreases in $k_{p}$. Thus, for any $k_{s}$ that the firm chooses, the firm can always increase its profits by lowering $k_{p}$, while always maintaining incentive compatibility ((IC-e) does not depend on $k_{p}$ ). Thus, $k_{s}<k_{p}$ can never be optimal. 
Proof of Proposition 2. Note that in any optimal contract, (IC-g) can never be binding because the firm could reduce bonuses without affecting the managers' effort and truth-telling decision. The same argument implies that (at least) one of the limited liability constraints (LL) must be binding.

Firstly, suppose that in the optimal contract $k_{s} \geq k_{p}$. Then, the binding limited liability constraint is $k_{0}+k_{p} z_{2} \geq 0$, implying $k_{0}=-k_{p} z_{2}$ in optimum. Inserting $k_{0}$ in the firm's profit function $(\mathrm{P})$ gives $\Pi(k)=\left(1-k_{s}-k_{p}\right) V+2 k_{p} z_{2}=V-k_{s} V-k_{p}\left(V-2 z_{2}\right)$. For $q \geq q_{d}$, we have $V-2 z_{2} \geq 0$. In this situation, $\Pi(k)$ decreases in $k_{s}$ and $k_{p}$, implying that the firm chooses $k_{s}$ and $k_{p}$ as low as possible. Thus, (IC-e) and (IC-b) bind at optimality, giving $k_{s}=\frac{8 c}{(2 q-1)\left(v_{2}-z_{2}\right)}$ and $k_{p}=\frac{(1-q) v_{2}+q z_{2}}{q\left(v_{2}-v_{1}\right)+(1-q) v_{1}+(1-q)\left(z_{2}-z_{1}\right)+q z_{1}} \cdot k_{s}$. For $q<q_{d}$, we have $V-2 z_{2}<0$. In this situation, $\Pi(k)$ decreases in $k_{s}$, but increases in $k_{p}$. Thus, the firm chooses $k_{p}$ as high as possible. Given $k_{s} \geq k_{p}$, this implies $k_{p}=k_{s}$, i.e., both limited liability constraints (LL) are binding. Inserting $k_{p}=k_{s}$ into $\Pi(k)$ yields $\Pi(k)=V-2 k_{s}\left(V-z_{2}\right)$. Since $V-z_{2}>0, k_{s}$ is chosen as low as possible; i.e., by (IC-e), $k_{s}=\frac{8 c}{(2 q-1)\left(v_{2}-z_{2}\right)}$. Lastly, the firm never chooses $k_{s}<k_{p}$ by the same argument as in Lemma 3.

Proof of Corollary 1. Suppose $q \geq q_{d}$. To show that $k_{s}^{*}>k_{p}^{*}$, it is sufficient to verify that $\frac{(1-q) v_{2}+q z_{2}}{q\left(v_{2}-v_{1}\right)+(1-q) v_{1}+(1-q)\left(z_{2}-z_{1}\right)+q z_{1}}<1$. Rearranging this inequality and solving for $q$ assures
that the condition holds for any $q>1 / 2$. To show that $k_{p}^{*} / k_{s}^{*}$ decreases concavely in $q$, convex decreases in $v_{2}$, and is invariant in $c$, we analyze first- and second-order partial derivatives of $\frac{k_{p}^{*}}{k_{s}^{*}}=\frac{(1-q) v_{2}+q z_{2}}{q\left(v_{2}-v_{1}\right)+(1-q) v_{1}+(1-q)\left(z_{2}-z_{1}\right)+q z_{1}}$ with respect to $q, v_{2}$, and $c$, respectively. It is easy to see that $k_{p}^{*} / k_{s}^{*}$ is independent of $c$. In addition, differentiation yields $\frac{\partial}{\partial q} \frac{k_{p}^{*}}{k_{s}^{*}}=$ $\frac{-\left(v_{2}+z_{2}\right)\left(v_{2}-v_{1}-z_{2}+z_{1}\right)}{\left[q\left(v_{2}-v_{1}\right)+(1-q) v_{1}+(1-q)\left(z_{2}-z_{1}\right)+q z_{1}\right]^{2}}<0$, and $\frac{\partial^{2}}{\partial q^{2}} \frac{k_{p}^{*}}{k_{s}^{*}}=\frac{2\left[\left(2 v_{1}-v_{2}\right)-\left(2 z_{1}-z_{2}\right)\right]}{q\left(v_{2}-v_{1}\right)+(1-q) v_{1}+(1-q)\left(z_{2}-z_{1}\right)+q z_{1}} \cdot \frac{\partial}{\partial q} \frac{k_{p}^{*}}{k_{s}^{*}}<0$, where the first result follows from $v_{2}>v_{1}+z_{1}$. Similarly, $\frac{\partial}{\partial v_{2}} \frac{k_{p}^{*}}{k_{s}^{*}}=\frac{-(2 q-1)\left[(1-q)\left(v_{1}-z_{1}\right)+z_{2}\right]}{\left[q\left(v_{2}-v_{1}\right)+(1-q) v_{1}+(1-q)\left(z_{2}-z_{1}\right)+q z_{1}\right]^{2}}<$ 0, and $\frac{\partial^{2}}{\partial v_{2}^{2}} \frac{k_{p}^{*}}{k_{s}^{*}}=\frac{-2 q}{q\left(v_{2}-v_{1}\right)+(1-q) v_{1}+(1-q)\left(z_{2}-z_{1}\right)+q z_{1}} \cdot \frac{\partial}{\partial v_{2}} \frac{k_{p}^{*}}{k_{s}^{*}}>0$, which proves the claim.

Proof of Proposition 3. The manager: The contract scheme $k^{*}$ incentivizes each manager to exert high-effort product evaluation. Thus, each manager's expected utility is given by $U_{i}\left(k^{*}\right)=$ $\mathbb{E}\left[w_{i}\left(k^{*}\right)\right]-c$. Since, ex-ante, both products have the same expected market value, $\mathbb{E}_{\theta}\left(\nu_{i} \mid k^{*}\right)=$ $\left(q v_{2}+v_{1}+(1-q) z_{2}+z_{1}\right) / 4=V / 2$, manager $i$ 's expected wage is $\mathbb{E}\left[w_{i}\left(k^{*}\right)\right]=k_{0}^{*}+\left(k_{s}^{*}+\right.$ $\left.k_{p}^{*}\right) \mathbb{E}_{\theta}\left(\nu_{i} \mid k^{*}\right)=k_{0}^{*}+\left(k_{s}^{*}+k_{p}^{*}\right) V / 2$.

First, we show that $\mathbb{E}\left[w_{i}\left(k^{*}\right)\right]$ decreases in $q$. Note that $\frac{\partial k_{s}^{*}}{\partial q}=-\frac{2}{2 q-1} k_{s}^{*}$, and $\frac{\partial V}{\partial q}=\frac{1}{2}\left(v_{2}-z_{2}\right)$. Assume $q \geq q_{d}$. In this case, differentiating $\mathbb{E}\left[w_{i}\left(k^{*}\right)\right]$ with respect to $q$ gives $\frac{\partial \mathbb{E}\left[w_{i}\left(k^{*}\right)\right]}{\partial q}=$ $\frac{1}{2}\left[\frac{\partial k_{s}^{*}}{\partial q} V+k_{s}^{*} \frac{\partial V}{\partial q}+\frac{\partial k_{p}^{*}}{\partial q}\left(V-2 z_{2}\right)+k_{p}^{*} \frac{\partial V}{\partial q}\right]<0$. Because the third term is negative, it suffices to show that $k_{s}^{*}\left(1+\frac{k_{p}^{*}}{k_{s}^{*}}\right) \frac{\partial V}{\partial q}<-\frac{\partial k_{s}^{*}}{\partial q} V$. This is true because $k_{s}^{*}\left(1+\frac{k_{p}^{*}}{k_{s}^{*}}\right) \frac{\partial V}{\partial q}<k_{s}^{*}\left(v_{2}-z_{2}\right)<$ $2 V k_{s}^{*} \leq \frac{2}{2 q-1} V k_{s}^{*}=-\frac{\partial k_{s}^{*}}{\partial q} V$. Now, assume $q<q_{d}$. In this case, $\frac{\partial \mathbb{E}\left[w_{i}\left(k^{*}\right)\right]}{\partial q}=\frac{\partial k_{s}^{*}}{\partial q}\left(V-z_{2}\right)+k_{s}^{*} \frac{\partial V}{\partial q}=$ $-\frac{2}{2 q-1} k_{s}^{*}\left(V-z_{2}\right)+k_{s}^{*} \frac{\partial V}{\partial q}<0$, because $4\left(V-z_{2}\right)>v_{2}-z_{2}$.

Second, we show that $\mathbb{E}\left[w_{i}\left(k^{*}\right)\right]$ decreases in $v_{2}$. Note that $\frac{\partial k_{s}^{*}}{\partial v_{2}}=-\frac{1}{v_{2}-z_{2}} k_{s}^{*}$, and $\frac{\partial V}{\partial v_{2}}=\frac{1}{2} q$. Assume $q \geq q_{d}$. In this case, differentiating $\mathbb{E}\left[w_{i}\left(k^{*}\right)\right]$ with respect to $v_{2}$ gives $\frac{\partial \mathbb{E}\left[w_{i}\left(k^{*}\right)\right]}{\partial v_{2}}=$ $\frac{1}{2}\left[\frac{\partial k_{s}^{*}}{\partial v_{2}} V+k_{s}^{*} \frac{\partial V}{\partial v_{2}}+\frac{\partial k_{p}^{*}}{\partial v_{2}}\left(V-2 z_{2}\right)+k_{p}^{*} \frac{\partial V}{\partial v_{2}}\right]<0$. This is true because $\left(k_{s}^{*}+k_{p}^{*}\right) \frac{\partial V}{\partial v_{2}}=\left(k_{s}^{*}+k_{p}^{*}\right) \frac{q}{2}<$ 
$\left(k_{s}^{*}+k_{p}^{*}\right) \frac{q}{2}+k_{s}^{*} \frac{v_{1}+z_{1}-z_{2}}{v_{2}-z_{2}}<-\frac{\partial k_{s}^{*}}{\partial v_{2}} V-\frac{\partial k_{p}^{*}}{\partial v_{2}}\left(V-2 z_{2}\right)$. Now, assume $q<q_{d}$. In this case, $\frac{\partial \mathbb{E}\left[w_{i}\left(k^{*}\right)\right]}{\partial v_{2}}=\frac{\partial k_{s}^{*}}{\partial v_{2}}\left(V-z_{2}\right)+k_{s}^{*} \frac{\partial V}{\partial v_{2}}=-\frac{1}{v_{2}-z_{2}} k_{s}^{*}\left(V-z_{2}\right)+k_{s}^{*} \frac{q}{2}<0$, because $\frac{V-z_{2}}{v_{2}-z_{2}}=\frac{q}{2}+\frac{v_{1}+z_{1}-z_{2}}{v_{2}-z_{2}}$.

Lastly, we show that $U_{i}\left(k^{*}\right)$ increases linearly in $c$. Assume $q \geq q_{d}$. In this case, differentiating $U_{i}\left(k^{*}\right)$ with respect to $c$ gives $\frac{\partial U_{i}\left(k^{*}\right)}{\partial c}=\frac{1}{2} \frac{\partial k_{s}^{*}}{\partial c}\left[V+\frac{k_{p}^{*}}{k_{s}^{*}}\left(V-2 z_{2}\right)\right]-1>\frac{1}{2} \frac{\partial k_{s}^{*}}{\partial c} V-1=$ $\frac{2}{2 q-1}\left[q+\frac{v_{1}+z_{1}+z_{2}}{v_{2}-z_{2}}\right]-1>1$. Now, assume $q<q_{d}$. In this case, $\frac{\partial U_{i}\left(k^{*}\right)}{\partial c}=\frac{\partial k_{s}^{*}}{\partial c}\left(V-z_{2}\right)-1=$ $\frac{4}{2 q-1}\left[q+\frac{v_{1}+z_{1}-z_{2}}{v_{2}-z_{2}}\right]-1>1$.

The firm: The firm's expected profit is given by $(\mathrm{P})$ and can be rewritten as $\Pi\left(k^{*}\right)=$ $2 \cdot\left[\mathbb{E}_{\theta}\left(\nu_{i} \mid k^{*}\right)-\mathbb{E}\left[w_{i}\left(k^{*}\right)\right]\right]$. From the previous proof, we know that $\mathbb{E}\left[w_{i}\left(k^{*}\right)\right]$ decreases in $q$ and $v_{2}$, and increases in $c$, whereas $\mathbb{E}_{\theta}\left(\nu_{i} \mid k^{*}\right)$ increases in $q$ and $v_{2}$, and is invariant in $c$. Thus, it follows immediately that $\Pi\left(k^{*}\right)$ increases in $q$ and $v_{2}$, and decreases in $c$.

Proof of Proposition 4. Substituting $k_{0}^{*}, k_{s}^{*}$, and $k_{p}^{*}$ into (P) and comparing expected profits with $\Pi(k=(0,0))=v_{1}+z_{1}$ immediately gives $\zeta_{4}=\zeta_{1} \cdot \frac{(2 q-1)\left(v_{2}-z_{2}\right)}{4\left(V+\frac{k_{p}^{*}}{k_{s}^{*}}\left(V-2 z_{2}\right)\right)}$. Since $(2 q-1)\left(v_{2}-z_{2}\right)<$ $4 V$ and $(2 q-1)\left(v_{2}-z_{2}\right)<8\left(V-z_{2}\right)$, it follows $\zeta_{4}<\zeta_{1}$. Next, by example, we prove the claim that there exist parameter values such that $\zeta_{4}>\zeta_{2}$. Assume $q=1, v_{1}=10, v_{2}=19, z_{1}=1$, and $z_{2}=1.5$. Then, $\zeta_{4}=0.521>0.375=\zeta_{2}$, which establishes the result. Finally, we note that $\zeta_{4}$ is convex increasing in $q$.

Proof of Proposition 5. (i) Let $\Pi_{\text {out }}=\frac{1}{2}\left(q_{\text {out }} v_{2}+v_{1}+\left(1-q_{\text {out }}\right) z_{2}+z_{1}\right)-2 c_{\text {out }}$ be the firm's expected profit under outsourcing. The firm prefers an in-house product evaluation if and only if $\Pi(c, q) \geq \Pi_{\text {out }}$. From the Implicit Function Theorem, we know that there exists a unique threshold function, $\bar{q}(c)$, such that $\Pi(c, \bar{q}(c))=\Pi_{\text {out }}$. Since $\Pi(c, q)$ increases in $q$, it follows that an in-house product evaluation is optimal if and only if $q \geq \bar{q}(c)$.

(ii)-(iii) The ordering of the threshold functions, $\bar{q}(c) \geq \bar{q}^{M H}(c)>\bar{q}^{A S}(c)=\bar{q}^{F B}(c)$, follows from Propositions 1 and 2 together with Lemma 3. Using implicit differentiation and the results of Proposition 3, we find that $\frac{\partial \bar{q}(c)}{\partial c}=-\frac{\partial \Pi}{\partial c} / \frac{\partial \Pi}{\partial q}>0$. Also, $\frac{\partial^{2} \bar{q}(c)}{\partial c^{2}}=\frac{\partial^{2} \Pi}{\partial c \partial q} \cdot \frac{\partial \Pi}{\partial c} /\left(\frac{\partial \Pi}{\partial q}\right)^{2} \leq 0$ if and only if $\frac{\partial^{2} \Pi}{\partial c \partial q} \geq 0$, what we verify in the remainder. Note that $\Gamma \equiv 4\left(V-z_{2}\right)-2(2 q-1) \frac{\partial V}{\partial q}>0$. For $q<q_{d}$, we have $\frac{\partial^{2} \Pi}{\partial c \partial q}=\frac{1}{2 q-1} \cdot \frac{\partial k_{s}^{*}}{\partial c} \cdot \Gamma>0$. Similarly, for $q \geq q_{d}, \frac{\partial^{2} \Pi}{\partial c \partial q}>\frac{1}{2(2 q-1)} \cdot \frac{\partial k_{s}^{*}}{\partial c} \cdot \Gamma>0$. With pure moral hazard, for $q \geq q_{d}, \frac{\partial^{2} \Pi}{\partial c \partial q}=\frac{1}{2(2 q-1)} \cdot \frac{\partial k_{s}^{*}}{\partial c} \cdot \Gamma>0$. With pure adverse selection the firm can realize first-best profits and $\frac{\partial^{2} \Pi^{F B}}{\partial c \partial q}=0$.

Lastly, it is sufficient to show that $\frac{\partial \bar{q}(c)}{\partial c}>\frac{\partial \bar{q}^{A S}(c)}{\partial c}$ and $\frac{\partial \bar{q}^{M H}(c)}{\partial c}>\frac{\partial \bar{q}^{A S}(c)}{\partial c}$ for maximum $c$. Note that $\frac{\partial \bar{q}^{A S}(c)}{\partial c}=\frac{4}{v_{2}-z_{2}}$. For $q<q_{d}, \lim _{c \rightarrow \infty} \frac{\partial \bar{q}(c)}{\partial c}=\frac{8}{v_{2}-z_{2}}$. For $q \geq q_{d}$, let $c_{\max }=$ $\bar{q}^{-1}(1)$. Then, $\frac{\partial \bar{q}\left(c_{\max }\right)}{\partial c}>\frac{4}{v_{2}-z_{2}}$. Lastly, with pure moral hazard, for $q \geq q_{d}, \lim _{c \rightarrow \infty} \frac{\partial \bar{q}^{M H}(c)}{\partial c}=$ $\frac{4}{v_{2}-z_{2}}$.

Proof of Proposition 6. To prove the claim, we note the following: (i) If $e=(l, l)$, then $n=$ $n^{F B}=2$; (ii) if $e=(h, l)$, then $n^{F B}=1$; and (iii) if $e=(h, h)$, then $n=n^{F B}=1.5$. Combining this observation with Propositions 1 and 4 concludes the proof: For $q<q_{c}, n-n^{F B}=0.5$ if $\zeta_{4} \leq c \leq \zeta_{1}$, and 0 otherwise; for $q \geq q_{c}, n-n^{F B}=0.5$ if $\min \left\{\zeta_{2}, \zeta_{4}\right\} \leq c<\max \left\{\zeta_{2}, \zeta_{4}\right\}, 1$ if $\max \left\{\zeta_{2}, \zeta_{4}\right\} \leq c \leq \zeta_{3}$, and 0 otherwise. 
Proof of Proposition 7. We begin with investigating $\eta_{p}$ for all five regions indicated in Figure 4. (i) $e^{f b}=e^{*}=(h, h)$ : In this case, $\eta_{p}=1-\frac{\Pi\left(e^{*}\right)}{\Pi\left(e^{*}\right)+U_{i}\left(e^{*}\right)+U_{j}\left(e^{*}\right)} \cdot \frac{\Pi\left(e^{*}\right)+U_{i}\left(e^{*}\right)+U_{j}\left(e^{*}\right)}{\Pi^{f b}\left(e^{f b}\right)}>0$. It can be readily verified that the second fraction is equal to one, and by applying Proposition 3 , the first fraction increases in $q$ and $v_{2}$, and decreases in $c$. It follows immediately that $\eta_{p}$ decreases in $q$ and $v_{2}$, and increases in $c$. (ii) $e^{f b}=e^{*}=(l, l)$ : In this case, $\eta_{p}=1-\frac{v_{1}+z_{1}}{v_{1}+z_{1}}=0$. (iii) $e^{f b}=(h, h)$, $e^{*}=(l, l)$ : In this case, $\eta_{p}=1-\frac{v_{1}+z_{1}}{\frac{1}{2}\left(q v_{2}+v_{1}+(1-q) z_{2}+z_{1}\right)-2 c}>0$, which increases in $q$ and $v_{2}$, and decreases in $c$. (iv) $e^{f b}=(h, l), e^{*}=(l, l)$ : In this case, $\eta_{p}=1-\frac{v_{1}+z_{1}}{\frac{1}{4}\left((2 q+1) v_{2}+(3-2 q) z_{2}\right)-c}>0$, which increases in $q$ and $v_{2}$, and decreases in $c$. (v) $e^{f b}=(h, l), e^{*}=(h, h):$ In this case, $\eta_{p}=1-\frac{\Pi\left(e^{*}\right)}{\Pi\left(e^{*}\right)+U_{i}\left(e^{*}\right)+U_{j}\left(e^{*}\right)} \cdot \frac{\Pi\left(e^{*}\right)+U_{i}\left(e^{*}\right)+U_{j}\left(e^{*}\right)}{\Pi^{f b}\left(e^{f b}\right)}>0$. As already argued in case (i), the first fraction increases in $q$ and $v_{2}$, and decreases in $c$. Now, by noting that over-investment can only occur if $c>\zeta_{2}$, we can readily verify that the same is true for the second fraction. Thus, $\eta_{p}$ decreases in $q$ and $v_{2}$, and increases in $c$. Finally, we note that the firm under-invests in product evaluation in cases (iii) and (iv), while an over-investment occurs solely in case (v).

We now turn to $\eta_{w}$. If $e^{*}=e^{f b}$, then $\Pi\left(e^{*}\right)+U_{i}\left(e^{*}\right)+U_{j}\left(e^{*}\right)=\Pi^{f b}\left(e^{f b}\right)$, and $\eta_{w}=0$. If the firm over-invests in product evaluation, $e^{*}=(h, h)$ and $e^{f b}=(h, l)$, then $\eta_{w}=1-$ $\frac{\Pi\left(e^{*}\right)+U_{i}\left(e^{*}\right)+U_{j}\left(e^{*}\right)}{\Pi^{f b}\left(e^{f b}\right)}>0$ decreases in $q$ and $v_{2}$, and increases in $c$ by the argument given in (v). Lastly, if the firm under-invests in product evaluation, $e^{*}=(l, l)$, compared to the first-best case, $e^{f b}=(h, h)$ or $e^{f b}=(h, l)$, then the percentage welfare loss, $\eta_{w}=1-\frac{v_{1}+z_{1}}{\frac{1}{2}\left(q v_{2}+v_{1}+(1-q) z_{2}+z_{1}\right)-2 c}>0$ or $\eta_{w}=1-\frac{v_{1}+z_{1}}{\frac{1}{4}\left((2 q+1) v_{2}+(3-2 q) z_{2}\right)-c}>0$, increases in $q$ and $v_{2}$, and decreases in $c$.

\section{References}

Adams, J. S. 1963. Toward an understanding of inequity. Journal of Abnormal and Social Psychology 67(5) 422-436.

Aggarwal, R. K., A. A. Samwick. 1999. Executive compensation, strategic competition, and relative performance evaluation: Theory and evidence. The Journal of Finance 54(6) 19992043.

Akerlof, G. A., J. L. Yellen. 1988. Fairness and unemployment. American Economic Review 78(2) 44-49.

Akerlof, G. A., J. L. Yellen. 1990. The fair-wage effort hypothesis and unemployment. The Quarterly Journal of Economics 105(2) 255-284.

Beinhocker, E. D. 1999. Robust adaptive strategies. Sloan Management Review 40(3) 95-106.

Bernardo, A. E., H. Cai, J. Luo. 2001. Capital budgeting and compensation with asymmetric information and moral hazard. Journal of Financial Economics 61(3) 311-344.

Bolton, G. E., A. Ockenfels. 2000. Erc: A theory of equity, reciprocity, and competition. American Economic Review 90(1) 166-193. 
Boudreau, K. J., K. R. Lakhani, N. Lacetera. 2011. Incentives and problem uncertainty in innovation contests: An empirical analysis. Management Science 57(5) 843-863.

Campbell, A., F. Ederer, J. Spinnewijn. 2014. Delay and deadlines: Freeriding and information revelation in partnerships. American Economic Journal: Microeconomics 6(2) 163-204.

Chao, R. O., S. Kavadias, C. Gaimon. 2009. Revenue driven resource allocation: Funding authority, incentives, and new product development portfolio management. Management Science 55(9) 1556-1569.

Chao, R. O., K. C. Lichtendahl Jr., Y. Grushka-Cockayne. 2013. Incentives in a stage-gate process. Production and Operations Management Forthcoming.

Ederer, F. 2013. Incentives for parallel innovation. Yale School of Management Working Paper.

Fehr, E., K. M. Schmidt. 1999. A theory of fairness, competition, and cooperation. The Quarterly Journal of Economics 114(3) 817-868.

Friebel, G., M. Raith. 2010. Resource allocation and organizational form. American Economic Journal: Microeconomics 2(2) 1-33.

Held, S., C. Bolte, M. Bierbaum, O. Schöffski. 2009. Impact of Big Pharma organizational structure on RED productivity. Books on Demand, Norderstedt, Germany.

Holmstrom, B. 1979. Moral hazard and observability. The Bell Journal of Economics 10(1) 74-91.

Holmstrom, B., P. Milgrom. 1987. Aggregation and linearity in the provision of intertemporal incentives. Econometrica 55(2) 303-328.

Huckman, R. S., G. P. Pisano, M. Rennella. 2010. Wyeth Pharmaceuticals: Spurring Scientific Creativity with Metrics. Harvard Business School case no. 9-607-008. Harvard Business School Publishing, Boston, MA.

Huckman, R. S., E. P. Strick. 2010. GlaxoSmithKline: Reorganizing Drug Discovery (A). Harvard Business School case no. 9-605-074. Harvard Business School Publishing, Boston, MA.

Hutchison-Krupat, J., S. Kavadias. 2013. Strategic resource allocation processes: Top-down, bottom-up, and the value of strategic buckets. Management Science Forthcoming.

Inderst, R., C. Laux. 2005. Incentives in internal capital markets: Capital constraints, competition, and investment opportunities. The RAND Journal of Economics 36(1) 215-228.

Kavadias, S., R. O. Chao. 2007. Resource allocation and new product development portfolio management. C. H. Loch, S. Kavadias, eds., Handbook of New Product Development Management, chap. 6. Butterworth-Heinemann, Oxford, UK, 135-164. 
Klingebiel, R., C. Rammer. 2014. Resource allocation strategy for innovation portfolio management. Strategic Management Journal 35(2) 246-268.

Kornish, L. J., K. T. Ulrich. 2011. Opportunity spaces in innovation: Empirical analysis of large samples of ideas. Management Science 57(1) 107-128.

Lambert, R. A. 1986. Executive effort and selection of risky projects. The RAND Journal of Economics 17(1) 77-88.

Lerner, J. 2012. The architecture of innovation: The economics of creative organizations. Harvard Business Press, Boston, MA.

Loch, C. H., A. DeMeyer, M. Pich. 2006. Managing the Unknown: A New Approach to Managing High Uncertainty and Risk in Projects. John Wiley \& Sons, Hoboken, NJ.

Loch, C. H., C. Terwiesch, S. Thomke. 2001. Parallel and sequential testing of design alternatives. Management Science 45(5) 663-678.

Mihm, J. 2010. Incentives in new product development projects and the role of target costing. Management Science 56(8) 1324-1344.

Mihm, J., C. H. Loch, D. Wilkinson, B. A. Huberman. 2010. Hierarchical structure and search in complex organizations. Management Science 56(5) 831-848.

Nelson, R. R. 1961. Uncertainty, learning, and the economics of parallel research and development efforts. The Review of Economics and Statistics 43(4) 351-364.

Rotemberg, J. J., G. Saloner. 1994. Benefits of narrow business strategies. American Economic Review 84(5) 1330-1349.

Sharpe, P., T. Keelin. 1998. How smithkline beecham makes better resource-allocation decisions. Harvard Business Review 76(2) 45-57.

Siemsen, E. 2008. The hidden perils of career concerns in r\&d organizations. Management Science 54(5) 863-877.

Siemsen, E., S. Balasubramanian, A. V. Roth. 2007. Incentives that induce task-related effort, helping, and knowledge sharing in workgroups. Management Science 53(10) 1533-1550.

Sommer, S. C., C. H. Loch. 2004. Selectionism and learning in projects with complexity and unforeseeable uncertainty. Management Science 50(10) 1334-1347.

Sommer, S. C., C. H. Loch. 2009. Incentive contracts in projects with unforeseeable uncertainty. Production and Operations Management 18(2) 185-196.

Sommer, S. C., C. H. Loch, J. Dong. 2009. Managing complexity and unforeseeable uncertainty in startup companies: An empirical study. Organization Science 20(1) 118-133. 
Stein, J. C. 1997. Internal capital markets and the competition for corporate resources. The Journal of Finance 52(1) 111-133.

Stein, J. C. 2002. Information production and capital allocation: Decentralized versus hierarchical firms. The Journal of Finance 57(5) 1891-1921.

Terwiesch, C., Y. Xu. 2008. Innovation contests, open innovation, and multiagent problem solving. Management Science 54(9) 1529-1543.

Thomas, C. 2011. Too many products: Decentralized decision making in multinational firms. American Economic Journal: Microeconomics 3(1) 280-306.

Thomke, S. 2007. Learning by experimentation: Prototyping and testing. C. Loch, S. Kavadias, eds., Handbook of New Product Development Management, chap. 15. ButterworthHeinemann, Oxford, UK, 401-420.

Xiao, W., Y. Xu. 2012. The impact of royalty contract revision in a multistage strategic r\&d alliance. Management Science 58(12) 2251-2271. 